\title{
Physical simulation of residual oil displacement production in offshore strong bottom water reservoir
}

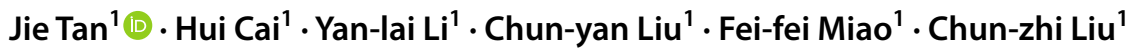

Received: 2 August 2021 / Accepted: 8 September 2021 / Published online: 22 September 2021

(c) The Author(s) 2021

\begin{abstract}
The $\mathrm{C}$ oilfield is located in the Bohai Bay Basin, a typical strong bottom water reservoir. Oilfield reservoir and oil-water distribution are complex. At present, the $\mathrm{C}$ oilfield has entered the high water cut development stage, and it is challenging to stabilize oil and control water. The reservoir with an imperfect well pattern has dominant bottom water ridge channels, uneven oil-water interface uplift, limited water drive sweep range, and low inter-well reservoir production degree. The oil layer between the horizontal section of the production well and the top of the reservoir cannot be effectively developed, and the remaining oil is enriched. Therefore, it is urgent to explore new energy supplement methods to improve inter-well and vertical remaining oil production in the $\mathrm{C}$ oilfield. In this study, the displacement medium is optimized through indoor experimental simulation. From the experimental results, the remaining oil between the sand bodies can be used in heavy oil reservoirs, and the residual oil between wells can be significantly utilized in the alternate displacement of gas and foam, and the recovery degree of the reservoir is increased by $12.44 \%$. The remaining oil at the top of the reservoir can be used in the upper reservoir to increase the remaining oil in the top of the reservoir by injecting gas and foam alternately in the new reservoir. The final recovery of the reservoir is increased by $6.00 \%$. This experimental study guides tapping the potential of the remaining oil in the offshore strong bottom water reservoir.
\end{abstract}

Keywords Offshore strong bottom water reservoir · Remaining oil · Water injection $\cdot$ Nitrogen foam injection $\cdot$ Physical simulation

\section{Introduction}

The $\mathrm{C}$ oilfield is located in the Western Bohai Sea, and the regional structure is located in Shaleitian uplift. The primary development strata of the oilfield are the Minghuazhen and the Guantao reservoir, which are high porosity and high permeability reservoirs. The central buried depth of the reservoir is $640 \sim 1750 \mathrm{~m}$, the formation temperature gradient is $3.3^{\circ} \mathrm{C} / 100 \mathrm{M}$, and the formation pressure gradient is $1.0 \mathrm{MPa} / 100 \mathrm{~m}$, belonging to the average temperature and pressure system. After nearly 10 years of high-speed development, it has wholly entered the high water cut period. Its primary development mode is to rely on natural energy exploitation driven by the strong edge and bottom water. Horizontal wells mainly develop it. The main production

Jie Tan

4687610@qq.com

1 Tianjin Branch of CNOOC Ltd, Tianjin, China characteristics are high water cut of oil wells and large liquid production of single wells. To achieve high efficiency and stable production, we must deeply study oil stabilization and water control technology in the bottom water reservoir and formulate the development strategy of the bottom water reservoir.

Compared with other reservoirs, the bottom water reservoir has severe heterogeneity and high formation crude oil viscosity(Tran et al. 2019; Zhu and Cheng 2007; Lai 2018). More prominent is that the bottom water is more active, resulting in excellent development difficulty (Mancinelli et al. 2007; Andrews et al. 2011). In addition, bottom water's coning is exacerbated due to the high viscosity of this kind of crude oil and the significant difference in oil-water mobility. Therefore, the core problem of bottom water reservoir development is how to control the bottom water coning or inhibit the water coning, maintain the uniform displacement of bottom water, improve the water drive sweep efficiency, and prolong the anhydrous oil production period of oil wells as far as possible, to improve the yield of the bottom water 
reservoir (Austad et al. 2005; Hoteit and Firoozabadi 2009). At present, two kinds of methods are mainly used to suppress edge and bottom water coning. The first is regulating on-site production measures, including reasonable injection production speed control, well pattern improvement, and perforation location optimization. The second is to improve recovery technology, including horizontal well technology and displacement mining (top gas injection, polymer flooding, gas foam, steam flooding) (Mokhtari and Ayatollahi 2019; Myint and Firoozabadi 2015; Kumar et al. 2018).

In addition, there are some methods of chemical cone pressure: polymer injection, which can reduce the effective permeability of water in flooded areas without reducing the effective permeability of oil in oil-bearing areas. It can also increase the viscosity of displacement fluid and reduce the fingering and coning of displacement fluid. Oil in water emulsion is a selective plugging agent (Jacquelin and Erik 2020; Sharma et al. 2019). Oil in water emulsion is injected into the oil layer, which more enters the high permeability zone, inhibits the flow capacity of the fluid in the high permeability zone, and thus inhibits the bottom water coning. Foam is a fluidity control agent. It can increase the viscosity of the displacement fluid, the small flow ratio, and the efficiency of water flooding. Foam is also a blockage agent.

When injected into the bottom water layer, it can block the high permeability zone of the bottom water layer, reduce the permeability of the bottom water layer and inhibit the coning of bottom water. Squeezing the heavy oil added with surfactant into the water outlet layer can improve the oil saturation near the well, increase the oil phase permeability and reduce the water phase permeability (Puntervold et al. 2015; Gupta and Mohanty 2011). At the same time, the active agent in heavy oil makes the active oil form a water in oil emulsion with stable performance when it meets water to increase the resistance to water flow. At present, the widely used method is to inject a plugging agent in the upper part near the oil-water interface with specific process measures to form an "artificial diaphragm" near the well bottom to prevent and reduce bottom water coning. However, the diaphragm formation also restricts the supplement of bottom water to reservoir energy (Cobos and Sogaard 2020). This method should be cautious for offshore heavy oil reservoirs.

At present, the common oil stabilization and water control technologies are: (1) well pattern infill and optimized interlayer perforation. When the oilfield enters the high water cut development period, it is necessary to carry out infill drilling in the potential area with high residual oil saturation in the oilfield to increase the oil well points and reduce the height of the water cone and reduce the influence of water ridge. The location and degree of infilling well pattern are mainly determined according to the distribution range of remaining oil. Offshore oil wells are sparse, so there is much room for adjustment of further infilling well patterns. For horizontal wells, the perforation horizon is mainly located at the top of the reservoir, so the feasibility of improving the production interval is also low. The well network is an important way to use the remaining oil between wells. The remaining oil enrichment areas between wells, top, and interlayer should be considered(Bhatia et al. 2014). (2) The investigation shows that chemical water shutoff is adopted in all reservoirs. The fast water cone channel is restrained from realizing the uniform advance of bottom water through water plugging. Water shutoff can be used as the main water control measure in the early stage, but in the middle and late stage, with the widespread rise of the oil-water interface, chemical water shutoff can only be used as an auxiliary means of water control. The chemical pressure cone mainly includes: (i)Polymer injection. Polymer injection can reduce the effective permeability of water in water flooded areas without reducing the effective permeability of oil in oilbearing areas to increase the viscosity of displacement fluid and reduce the fingering and coning of displacement fluid. (ii)Oil in water emulsion. Oil in water emulsion is a selective plugging agent. After being injected into the reservoir, it will more enter the high permeability zone, inhibit the flow capacity of the fluid in the high permeability zone, and thus inhibit the bottom water coning. (iii)Foam flooding and profile control. Foam is a fluidity control agent, and it can increase the viscosity of the displacement fluid, reduce the mobility ratio, and increase the efficiency of water flooding. Foam is also a blockage agent. Foam is injected into the bottom water to block the hypertonic zone in the bottom water, thus inhibiting water cones. (iv)Alternately inject water and air to control and drive. The purpose of alternating water and air injection is to increase the saturation of free $g$ to reduce the relative permeability of the water phase and make the oil-water interface advance more evenly. (v)Squeeze the heavy oil added with surfactant into the water outlet layer. On the one hand, it can improve the oil saturation near the well, increase the oil phase permeability, and reduce the water phase permeability. On the other hand, the active agent in heavy oil can make the active oil form a water in oil emulsion with stable performance when it meets water to increase the resistance to water flow(Xu et al. 2016). (3) Shut-in and control cone. Shut-in is easy to operate, so it is used in most bottom water reservoirs. When the oil well is exploited, the water cone is formed due to production pressure differences. When the oil well is shut-in, the difference of oil-water specific gravity leads to the phenomenon of oil-water gravity differentiation, and the water cone gradually flattens until it disappears due to its gravity. Periodic well switching is beneficial to improve the development effect of the bottom water reservoir and can effectively use the capillary force of the reservoir to improve the oil displacement efficiency of the saddle between water cones. The well would be shut-in as little as possible to ensure the maximum production, but 


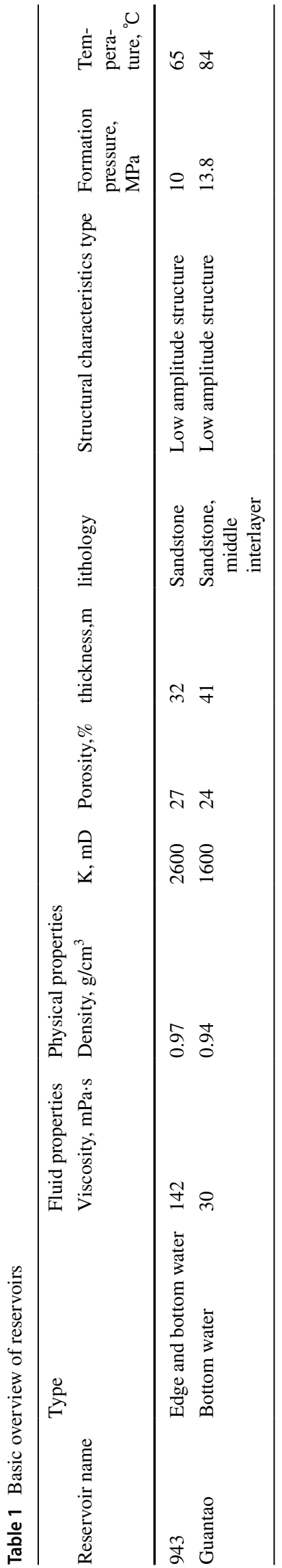

careful measures would be required to shut-in the well to ensure the maximum production(Zhang. 2011). (4) Drainage oil production. After the water cone or ridge formed by the bottom water of the reservoir is pushed toward the oil well, for the vertical well, the double pipe packer is used to seal the oil and water layer at the upper part of the oil-water interface. The main pipe is set at the oil layer for oil production, and the auxiliary pipe is set at the water layer for water production. If the single pipe packer is used, the oil pipe is used for water production, and the oil jacket annulus is used for oil production. For the horizontal well, the tailpipe or horizontal branch well is drilled at the lower part of the horizontal well; the lower liner or horizontal well is perforated and drained in the water layer, while the upper horizontal well is used for oil production (Moradi et al. 2013). (5) Change the displacement direction and eliminate the cone. In the bottom water drive reservoir, there is only one liquid flow direction from bottom to top. Topwater injection (or middle and lower gas injection) is adopted in other wells near the oil production to increase a lateral driving force to inhibit the bottom water cone from changing the vertical liquid flow direction and slowing down the water cone. Few reservoirs implement this scheme, which needs to be cautious (Ese et al. 2004). (6) Manual partition. It applies to the situation that the oil-water interface has not crossed the diaphragm. It is mainly used in the early or middle stage of oil well production. the widely used method is to inject a plugging agent in the upper part near the oil-water interface with certain process measures to form an "artificial diaphragm" near the bottom of the well. To prevent and reduce bottom water coning (Cai 2000). (7) Engineering pressure coning. Many engineering methods control bottom water coning, such as plugging in the formation, mixing thin oil, gas injection huff, and puff (Nasralla et al. 2015). (8) Horizontal sidetracking of high water cut oil wells. According to the motion law of bottom water coning, sidetracking horizontal wells are used to avoid bottom water coning. Drilling is especially suitable for reservoirs with more residual oil distribution between interlayers (Bartels et al. 2019; Li et al. 2007; Peng and Kang 2008). (9) Pilot water and gas injection test. Change the distribution of remaining oil through water injection and gas injection. We should fully play the advantages of gas water density difference, alternating water, and gas to control fluidity ratio and implement gas injection or water gas alternation (gas foam). However, the cost of gas injection and water-gas alternation is high, and the risk is great. First, the magnitude of the increase in gas injection rate and the technical and economic feasibility is demonstrated according to the reservoir's geological characteristics and fluid properties. Good scheme design and injection production parameter optimization are carried out ( $\mathrm{Li}$ et al. 2007; He et al. 2018; Mahani et al. 2017). 
Fig. 1 The preparation process of the rock plate test

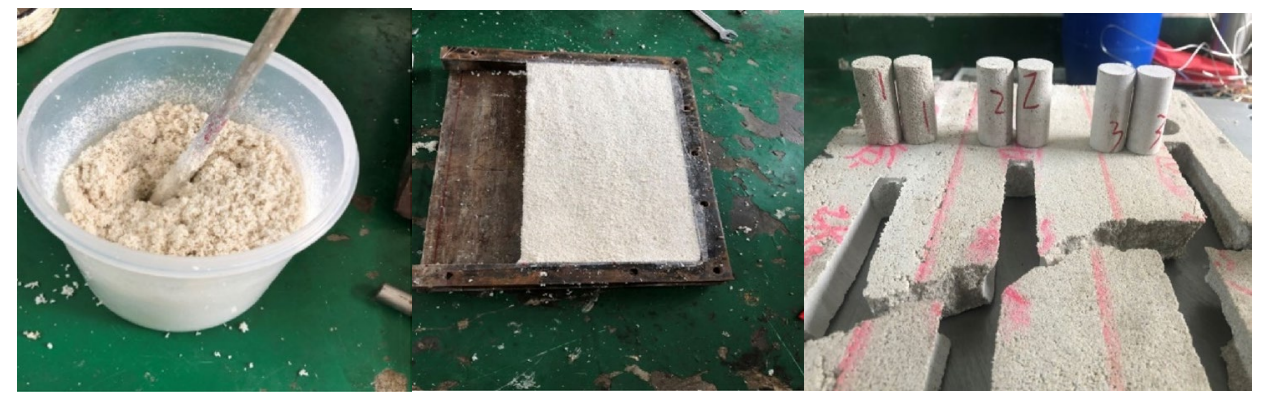

(c) Put the filled test rock

plate into the oven for drying

(a) Mix quartz sand, sealant and water evenly (b) Manually fill the test rock plate in the mold and then drill two plunger shaped small cores in each layer of the rock plate for permeability measurement

Table 2 Test datasheet

\begin{tabular}{|c|c|c|c|c|c|c|}
\hline $\begin{array}{l}\text { Number of } \\
\text { experiments }\end{array}$ & Unit height, $\mathrm{cm}$ & $\begin{array}{l}\text { Quartz sand } \\
\text { (40-70mesh), g }\end{array}$ & $\begin{array}{l}\text { Quartz sand (80- } \\
160 \text { mesh), g }\end{array}$ & $\begin{array}{l}\text { Sewing } \\
\text { agent glue, } \\
\mathrm{g}\end{array}$ & Water, $\mathrm{g}$ & $\begin{array}{l}\text { Perme- } \\
\text { ability, } \\
\mathrm{mD}\end{array}$ \\
\hline 1 & I & 130 & 30 & 15.0 & 1 & 8200 \\
\hline 2 & & & & 25.0 & & 6000 \\
\hline 3 & & & & 28.0 & & 5700 \\
\hline 4 & & & & 30.5 & & 2500 \\
\hline 5 & & & & 32.0 & & 1600 \\
\hline 6 & & & & 33.0 & & 1300 \\
\hline 7 & & & & 33.5 & & 800 \\
\hline 8 & & & & 34.0 & & 500 \\
\hline 9 & & & & 35.0 & & 15 \\
\hline
\end{tabular}

Table3 Experimental rock plate formula

\begin{tabular}{lllllll}
\hline Reservoirs & $\begin{array}{l}\text { Perme- } \\
\text { ability, } \\
\mathrm{mD}\end{array}$ & Unit height, cm & $\begin{array}{l}\text { Quartz sand } \\
(40-70 \mathrm{mesh}), \\
\mathrm{g}\end{array}$ & $\begin{array}{l}\text { Quartz sand } \\
(80-160 \\
\text { mesh), } \mathrm{g}\end{array}$ & $\begin{array}{l}\text { Sewing } \\
\text { agent } \\
\text { glue, g }\end{array}$ & Water,g \\
\hline The 943 reservoir & 500 & 1 & 130 & 30 & 34.0 & 1 \\
& 2500 & & & 30.5 & 1 \\
The Guantao reservoir & 800 & & & 33.5 & 1 \\
& 1600 & & & 32.0 & 1 \\
\hline
\end{tabular}

For the strong bottom water reservoir in the middle and late stage of offshore development, it is challenging to implement technologies such as perfect injection production pattern and steam displacement, which are mainly controlled by the excellent production system, perforation location optimization, and gas injection or gas foam mining technology based on existing well pattern. To fully demonstrate the feasibility of inter-well residual oil displacement, six groups of large-scale model oil displacement experiments (three interwell residual oil displacement physical simulations and three groups of top residual oil displacement physical simulation) were carried out. The displacement medium is optimized, and the optimization of displacement parameters is studied for the optimal displacement medium. Select the medium suitable for inter-well and top residual oil displacement in the $\mathrm{C}$ oilfield, and formulate a feasible scheme for interwell and top residual oil displacement development in the $\mathrm{C}$ oilfield. It guides tapping the potential of remaining oil in offshore strong bottom water reservoirs. 


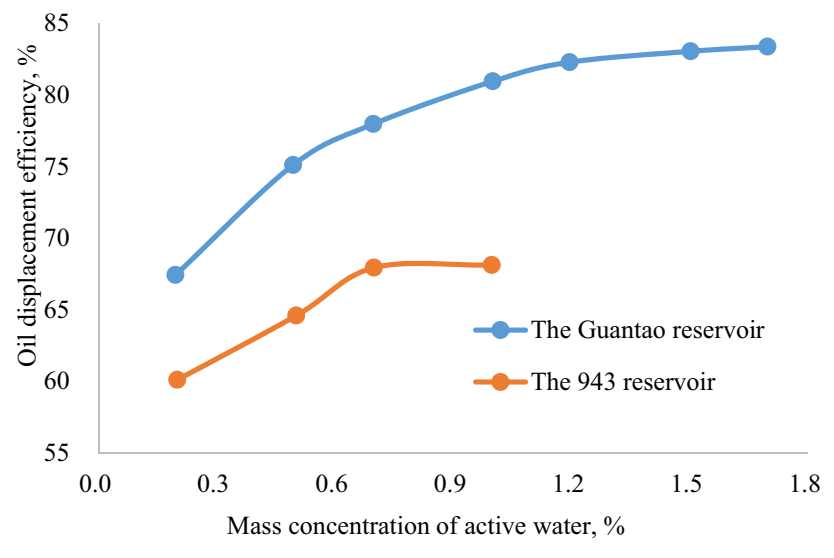

Fig. 2 Oil displacement efficiency of the 943 and Guantao reservoirs with different concentrations of active water

Table 4 Composition of simulated oil preparation

\begin{tabular}{llll}
\hline & $\begin{array}{l}\text { Lead isooc- } \\
\text { tanoate, } g\end{array}$ & $\begin{array}{l}\text { Lodine band } \\
\text { n-butane, } g\end{array}$ & White oil, g \\
\hline $\begin{array}{l}\text { The Guantao reser- } \\
\text { voir simulated oil }\end{array}$ & 60 & 40 & 30 \\
$\quad \begin{array}{l}-30 \mathrm{mPa} \cdot \mathrm{s} \\
\begin{array}{l}\text { The } 943 \mathrm{reservoir} \\
\text { simulated oil- }\end{array}\end{array}$ & 40 & 30 & 80 \\
\begin{tabular}{l}
$142 \mathrm{mPa} \cdot \mathrm{s}$ \\
\hline
\end{tabular} & & & \\
\hline
\end{tabular}

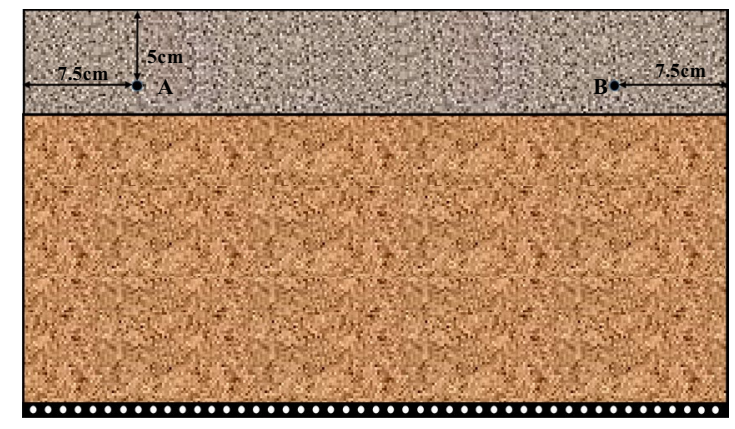

(a) The pattern of remaining oil displacement between wells in the Guantao reservoir

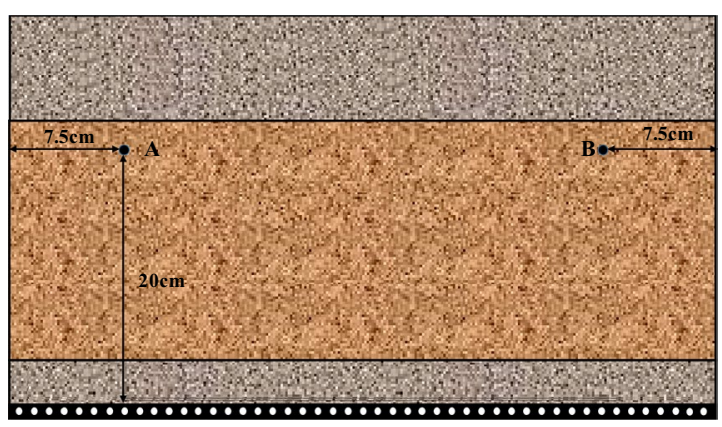

(b) Well layout of rock plate for residual oil displacement betw een wells in the 943 reservoir

Fig. 3 Well layout of residual oil displacement rock plate between sand bodies

\section{Core and fluid sample preparation}

\section{Basic overview of reservoirs}

This study takes the Guantao and 943 reservoirs in the C oilfield as the research object. The two reservoirs are low amplitude structures, and the temperature pressure system is standard. The Guantao reservoir is a strong bottom water reservoir with a viscosity of $30 \mathrm{mPa} \cdot \mathrm{s}$. The 943 reservoir is an edge and bottom water reservoir with a viscosity of $142 \mathrm{mPa} \cdot \mathrm{s}$. see Table 1 for detailed parameters.

\section{Core model preparation}

The large-size profile rock plate $(40 \mathrm{~mm} \times 300 \mathrm{~mm} \times 30 \mathrm{~mm})$ is made of quartz sand with different mesh numbers, different quality of crack sealant, and water, stirred evenly at room temperature and pressure, and then filled manually in the mold. Put the filled test rock plate into the oven for drying, and then drill two plunger-shaped small cores in each layer of the rock plate for permeability measurement. By controlling the single variable method, continuously adjust the proportion of quartz and fracture glue, and finally, fill the rock plate with the required permeability. See Fig. 1 for each process of rock plate test and Table 2 for test data.

According to the 9 groups of tests, the permeability decreases with the increase of glue content. The glue content per unit rock plate permeability of $500 \mathrm{mD}$ is $34.0 \mathrm{~g}$, the glue content per unit rock plate permeability of $800 \mathrm{mD}$ is $33.5 \mathrm{~g}$, the glue content per unit rock plate permeability of $1600 \mathrm{mD}$ is $32 \mathrm{~g}$, and the glue content per unit rock plate permeability of $2500 \mathrm{mD}$ is $30.5 \mathrm{~g}$. See Table 3 for the formula of rock plate used in the experiment.

\section{Fluid sample preparation}

The formation water used in the experiment is prepared according to the formation water quality. The water type of the 943 reservoir is calcium chloride type, and the average total salinity is $3975.7 \mathrm{mg} / \mathrm{L}$. The water type of the Guantao reservoir is also calcium chloride type, and the average total salinity is $4674.5 \mathrm{mg} / \mathrm{L}$. The mass concentration of active water used in the 943 reservoir displacement is $0.7 \%$. (active water is added with a new type of high permeability surfactant mixture system, which is mainly used to increase the viscosity of injected water and reduce the oil-water viscosity ratio), and the mass concentration of active water used for the Guantao reservoir displacement is 1.0\% (the 943 and the Guantao reservoirs). The oil displacement efficiency experiments of active water with different concentrations show that when active water concentration reaches $0.7 \%$ and $1.0 \%$, the increase of oil displacement efficiency decreases (see Fig. 2). The foam mass concentration of the 943 and the Guantao reservoirs is $0.35 \%$. 
Fig. 4 Experimental device.

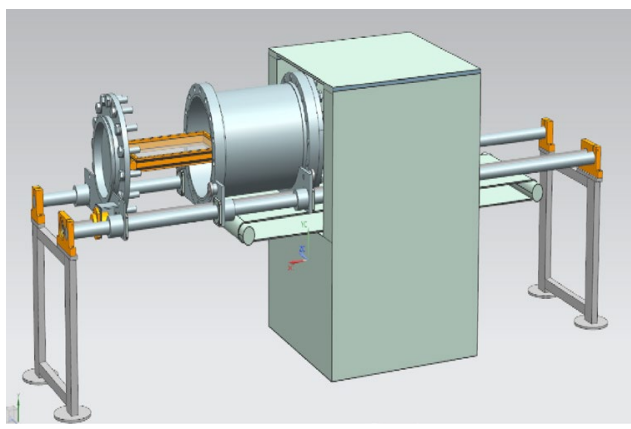

(a) Effect drawing of the general assembly

of aluminum alloy two-dimensional flat plate

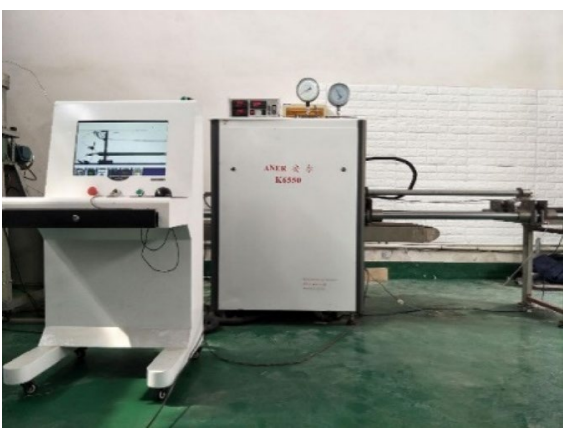

(b) ANERX-CT-K6550 scanner

holder and outer cylinder

The simulated oil used in the experiment comprises the iodo-n-butane, the lead isooctanoate, and the white oil in different proportions. See Table 4 for the mixing proportion. The purity of iodo-n-butane used as the dye of the fluid is $99 \%$. The lead isooctanoate is used to increase viscosity. Its purity is $98 \%$, and viscosity is $300 \mathrm{mPa} \cdot \mathrm{s}$. White oil is used to adjust viscosity, and its viscosity is $120 \mathrm{mPa} \cdot \mathrm{s}$.

\section{Physical simulation of inter-well residual oil displacement production}

\section{Establishment of the physical model of rock slab}

The fabrication specification of the Guantao reservoir rock plate is $40 \mathrm{~cm} \times 30 \mathrm{~cm} \times 3 \mathrm{~cm}$. The physical properties, rhythm, and well profile position of the rock plate are the Guantao reservoir. The vertical results of gas permeability of 3 production wells in the Guantao reservoir show positive rhythm characteristics and permeability level difference of 2-4 times, the vertical K rhythm characteristics of 5 exploration wells show positive rhythm characteristics and permeability level difference of 2-4 times, and the average permeability of the Guantao reservoir is $1600 \mathrm{mD}$. It can be determined that the permeability of the lower reservoir is $1600 \mathrm{mD}$, and the permeability of the upper reservoir is $800 \mathrm{mD}$. It is referring to the actual well group, the well spacing is $350 \mathrm{~m}$, located at the same depth of the upper reservoir, the thickness of the upper reservoir is about $13 \mathrm{~m}$, the horizontal well is located in the middle of the upper reservoir, and the total thickness of the reservoir is about $46.5 \mathrm{~m}$.

Fig. 5 Flow chart of rock plate experiment

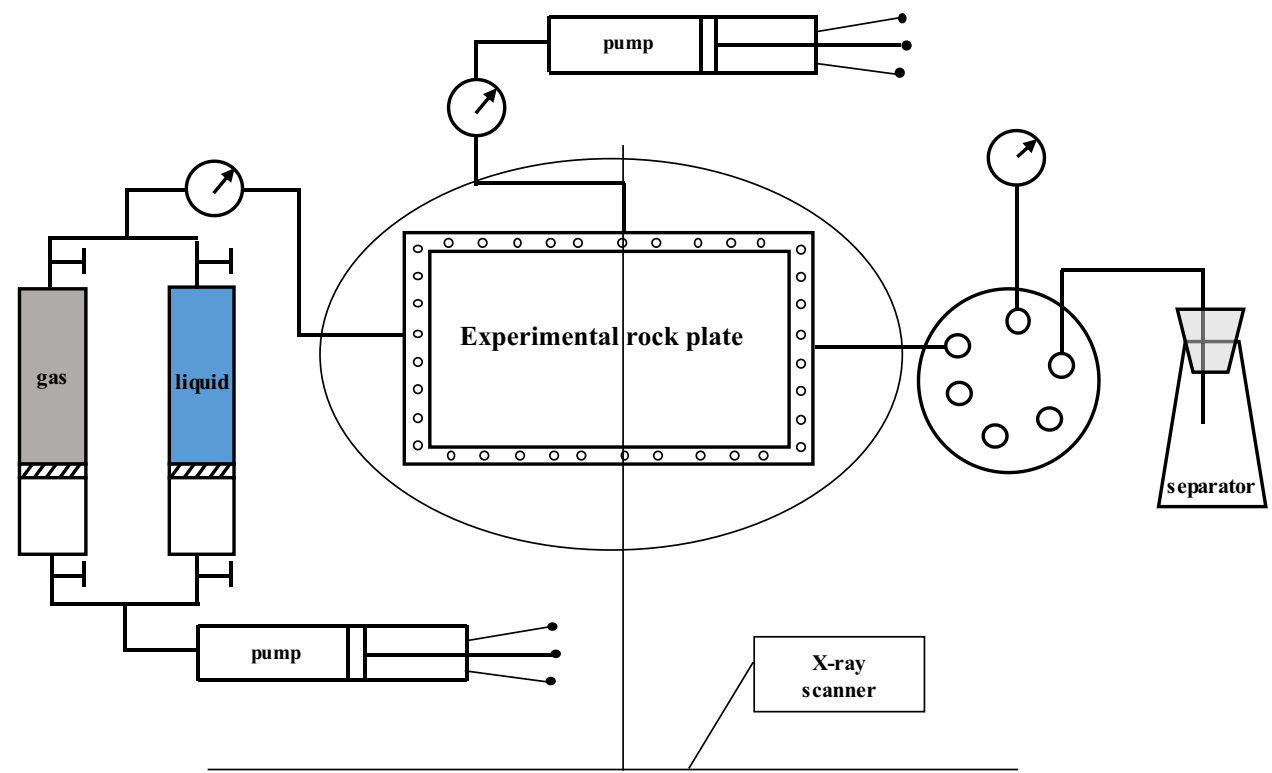


Combined with the permeability distribution characteristics, the ratio of the upper reservoir to the lower reservoir is 1:3.

The Guantao reservoir experimental rock plate is designed as two horizontal wells (the A and B wells) and a bottom water-screen. It is determined that the simulated thickness of the upper reservoir is $7 \mathrm{~cm}$, and the simulated thickness of the lower reservoir is $23 \mathrm{~cm}$. The two wells are located at a depth of $5 \mathrm{~cm}$ from the top and a radius of $2 \mathrm{~mm}$. They are $25-\mathrm{cm}$-apart and $7.5-\mathrm{cm}$-away from the left and right boundaries. See Fig. 3 a.

The 943 reservoir rock plate is $40 \mathrm{~cm} \times 30 \mathrm{~cm} \times 3 \mathrm{~cm}$. The physical properties, rhythm, and well profile position of the rock plate refer to the reservoir properties of the 943 reservoir. The vertical $\mathrm{K}$ rhythm of 7 production wells in the 943 reservoir is characterized by composite rhythm and staggered rhythm distribution. The permeability grade difference is 45 times, and the average permeability is $2600 \mathrm{mD}$. Therefore, the permeability of the upper reservoir is $500 \mathrm{mD}$; the permeability of the middle reservoir is $2500 \mathrm{mD}$; the permeability of the lower reservoir is $500 \mathrm{mD}$. The well spacing is $470 \mathrm{~m}$, the average thickness is about $8 \mathrm{~m}$, and the well location is located in the middle and upper part of the reservoir. Combined with the permeability distribution characteristics, it is determined that the top thickness accounts for about $1 / 3$ of the reservoir thickness. The 943 reservoir experimental rock plate is designed as two horizontal wells (the A and B wells) and a bottom water-screen. The depth between the two wells is $10 \mathrm{~cm}$ from the top, the upper reservoir accounts for about $1 / 4$ (the thickness of the upper reservoir is $7 \mathrm{~cm}$ ), the thickness of the lower reservoir accounts for $1 / 8$ (the design of the lower reservoir is $3 \mathrm{~cm}$ ), the well diameter is $2 \mathrm{~mm}$, the distance between them is $2 \mathrm{~m}$, and they are $75 \mathrm{~cm}$ from the left and right, as shown in Fig. $3 \mathrm{~b}$.

\section{Experimental scheme and process}

The physical simulation experiment temperature of cross well residual oil displacement production is $20^{\circ} \mathrm{C}$, the experimental pressure is $3 \mathrm{MPa}$, and the experimental instrument is the ANERX-CT-K6S0 scanner (as shown in Fig. 4). Three groups of experiments are designed. The first group of the Guantao reservoir active water displacement experiments, second sets of the Guantao reservoir gas foam alternate flooding experiment, third group the 943 reservoir gas foam alternate flooding experiment, the plan is as follows.

The first group of experiments: the Guantao reservoir rock plate is made according to the Guantao reservoir well pattern design. The formation water of the Guantao reservoir
Table 5 The Guantao reservoir active water flooding data

\begin{tabular}{|c|c|c|c|c|}
\hline $\begin{array}{l}\text { Injected hydrocarbon pore } \\
\text { volume, HCPV }\end{array}$ & Injection medium & $\begin{array}{l}\text { Differential pres- } \\
\text { sure, } \mathrm{MPa}\end{array}$ & $\begin{array}{l}\text { Recovery } \\
\text { degree, } \%\end{array}$ & Water cut, $\%$ \\
\hline 0.1 & \multirow[t]{15}{*}{ Formation water } & 0.32 & 13.89 & 0.00 \\
\hline 0.2 & & 0.38 & 22.55 & 13.91 \\
\hline 0.3 & & 0.37 & 27.85 & 35.76 \\
\hline 0.4 & & 0.37 & 31.99 & 62.08 \\
\hline 0.5 & & 0.37 & 34.79 & 72.55 \\
\hline 0.6 & & 0.35 & 36.50 & 80.20 \\
\hline 0.7 & & 0.35 & 37.90 & 83.70 \\
\hline 0.8 & & 0.31 & 39.05 & 86.86 \\
\hline 0.9 & & 0.38 & 40.06 & 88.87 \\
\hline 1.0 & & 0.35 & 40.75 & 92.39 \\
\hline 1.1 & & 0.28 & 41.24 & 93 \\
\hline 1.2 & & 0.35 & 41.58 & 95.01 \\
\hline 1.3 & & 0.31 & 41.83 & 96.58 \\
\hline 1.4 & & 0.33 & 41.99 & 98.16 \\
\hline 1.5 & & 0.37 & 42.03 & 99.22 \\
\hline 1.6 & \multirow[t]{4}{*}{ Active water } & 0.33 & 42.28 & 93.33 \\
\hline 1.7 & & 0.31 & 42.51 & 97.03 \\
\hline 1.8 & & 0.27 & 42.70 & 98.05 \\
\hline 1.9 & & 0.29 & 42.76 & 99.35 \\
\hline
\end{tabular}




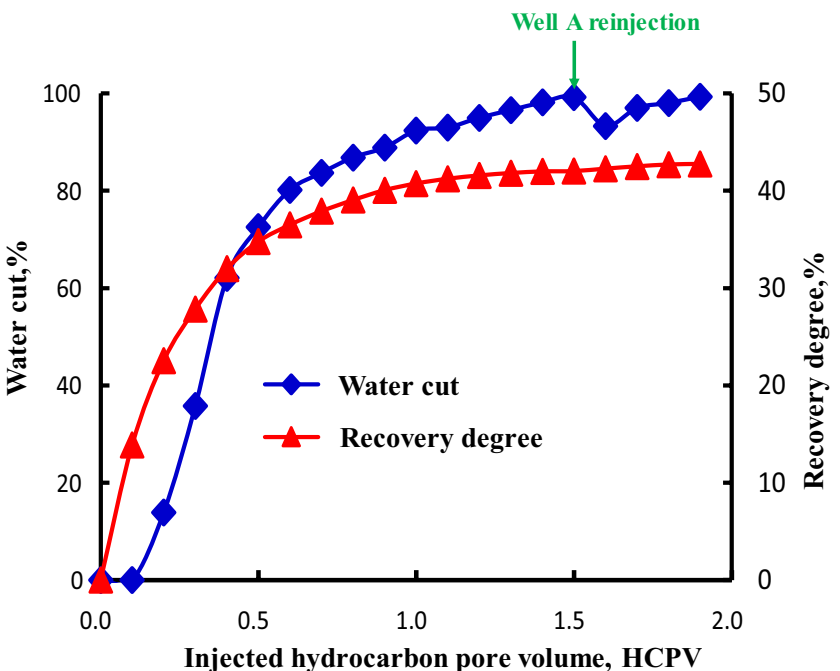

(a) Water cut and cumulative recovery vary with the pore volume of injected hydrocarbons

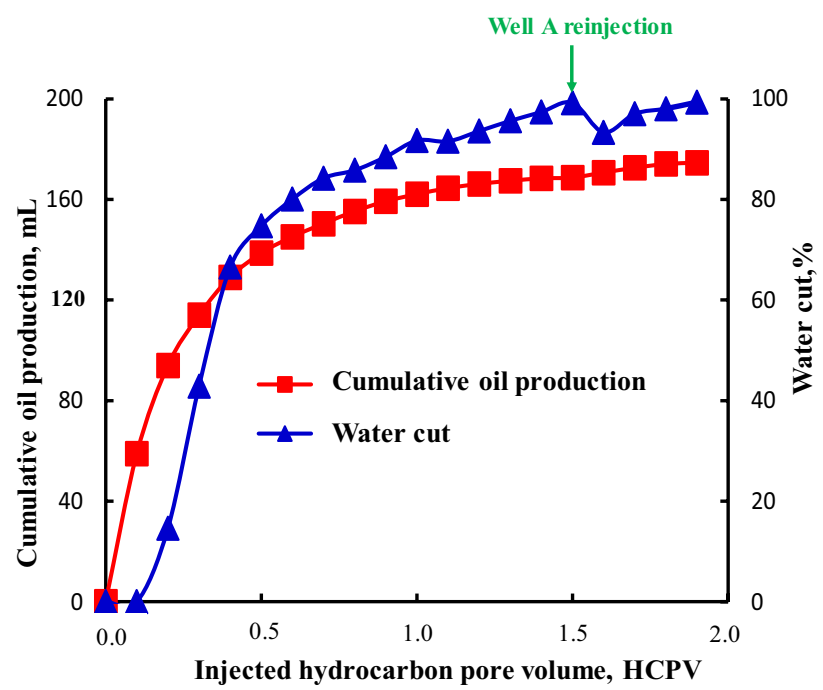

(c) The cumulative oil production and water cut of the B well vary with the pore volume of injected hydrocarbons

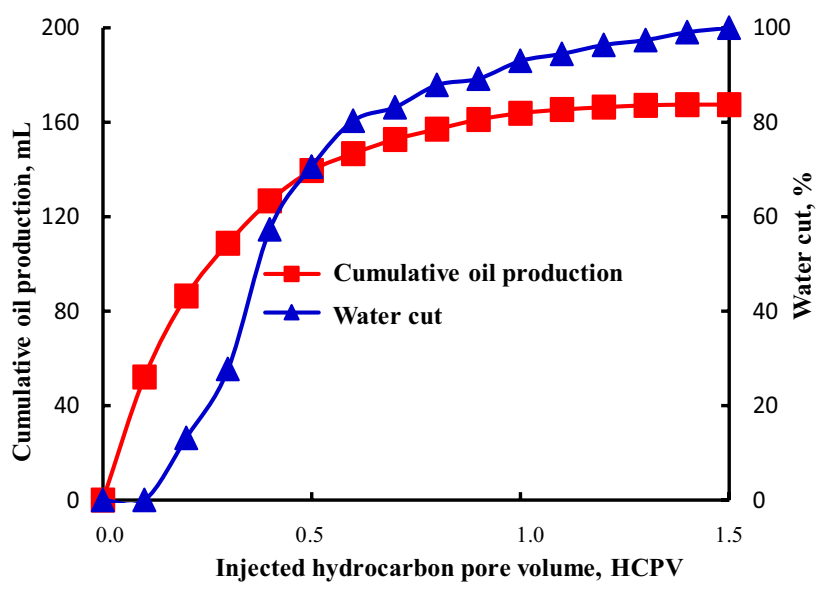

(b) The cumulative oil production and water cut of the A well vary with the pore volume of injected hydrocarbons

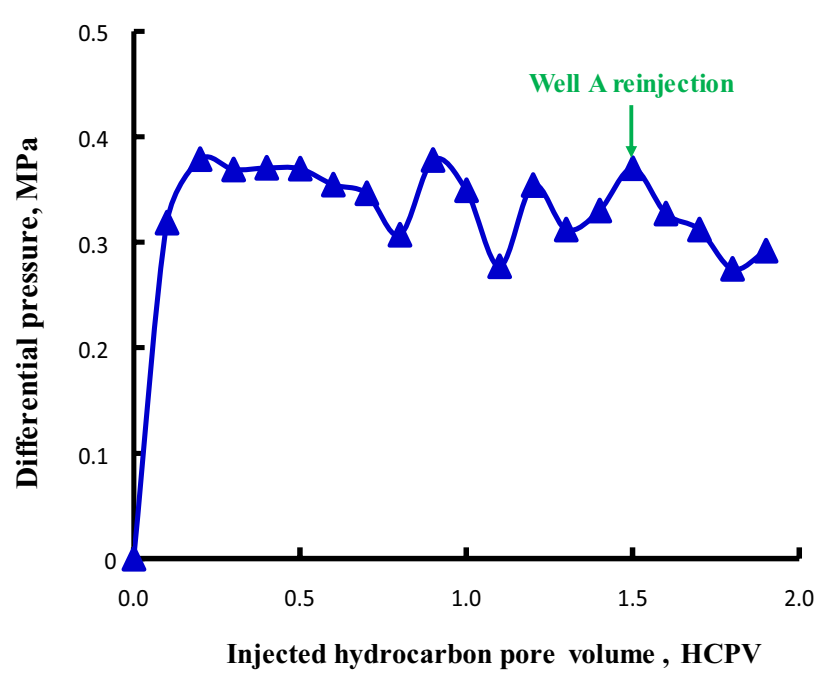

(d) Variation of production differential pressure with a pore volume of injected hydrocarbon

Fig.6 Dynamic data change of the Guantao reservoir active water displacement process

is injected at a constant speed ( $\mathrm{VmL} / \mathrm{min})$ from the bottom water inlet for displacement. For each injection of $0.1 \mathrm{HCPV}$, the input pressure, outlet pressure, confining pressure, and the amount of oil and water produced by the two production wells are recorded, and the experimental rock plate is sent to the X-ray machine for scanning. Calculate the water cut of the A and B wells. When the water cut of a well reaches more than $99 \%$, close the well and continue production until the A and B wells are closed and the water drive is completed. In the active water drive stage, select the A well as the injection to inject active water and the $\mathrm{B}$ well as the production well to drive and record the data until the water cut of the B well reaches more than $99 \%$ again.

The second group of experiments: to eliminate the experimental error, the Guantao reservoir rock plate is made again according to the Guantao reservoir well pattern design. The formation water of the Guantao reservoir is injected from the bottom water inlet at a constant speed $(\mathrm{VmL} / \mathrm{min})$ for displacement. For each injection of 0.1HCPV, the inlet pressure, outlet pressure, confining pressure, and the amount of oil and water produced by the two production wells are recorded, and the experimental sample board is sent to the 


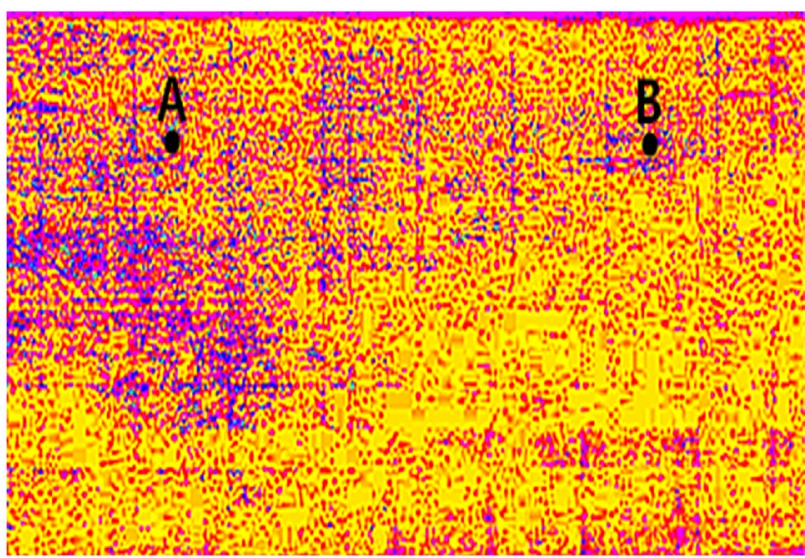

(a) Original rock sample

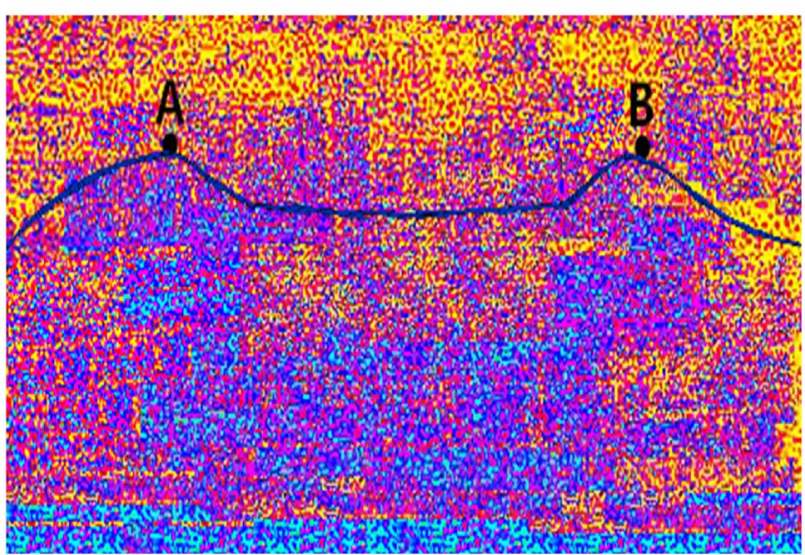

(b) End of water flooding

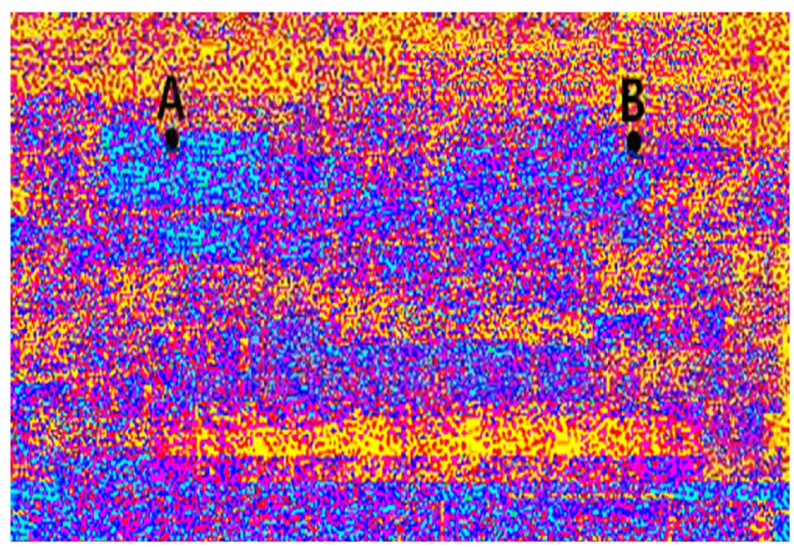

(c) end of active water flooding

Fig. 7 Active water displacement process of the Guantao reservoir

$\mathrm{X}$-ray machine for scanning. Calculate the water cut of the $\mathrm{A}$ and $\mathrm{B}$ wells. When the water cut of a well reaches more than $99 \%$, close the well and continue production until the $\mathrm{A}$ and $\mathrm{B}$ wells are closed and the water drive is completed.
In the alternate stage of gas and foam flooding, the A well is the injection, and the gas and foam of $0.1 \mathrm{HCPV}$ are alternately injected. The B Well is used as a production well for displacement and data recording. Stop production until the water cut of the B well reaches more than $99 \%$ again.

Three groups of experiments: the 943 reservoir rock plate is designed and made according to the 943 reservoir well pattern, and the formation water of the 943 reservoir is injected from the bottom water inlet at a constant rate $\left(\mathrm{V}_{1} \mathrm{~mL} / \mathrm{min}\right)$ for displacement. The inlet pressure, outlet pressure, confining pressure, and the oil, water, and gas output of the two production wells are recorded every $0.1 \mathrm{HCPV}$ injected. The experimental rock plate is sent to the X-ray machine for scanning: calculate the water cut of the A and B wells. When the water cut of a well reaches more than $99 \%$, close the well and continue production until the A and B wells are closed and the water drive is completed. In the alternate gas and foam flooding stage, the A well is injected into the 0.1HCPV. The B well as the injection well, and the displacement data are recorded. The production is stopped until the water cut of the B well reaches more than $99 \%$. The experimental process is as follows(see Fig. 5):

(1) Prepare oil samples and instruments.

Prepare the rock plate holder, install the rock plate into the rock plate holder according to the requirements, calibrate various instruments, clean and blow-dry, test pressure, vacuum, and keep it constant to the experimental value.

\section{(2) Establish bound water}

After vacuuming the rock plate, saturate the formation water at constant pressure, establish bound water after oil displacement, and record the injected water volume and water output in this process.

\section{(3) Saturation of oil sample}

Establish the system pressure and use the prepared oil sample to displace several times the pore volume. When the composition of the oil sample at the outlet is the same as that of the displaced oil sample, the sample is saturated and forms the original state.

\section{(4) Experiment}

According to the scheme design, different single-phase fluid continuous displacement experiments are carried out after the sample is saturated. 
Table 6 The gas and foam alternate flooding data of the Guantao reservoir

\begin{tabular}{|c|c|c|c|c|}
\hline $\begin{array}{l}\text { Injected hydrocarbon pore } \\
\text { volume, HCPV }\end{array}$ & Injection medium & $\begin{array}{l}\text { Differential pres- } \\
\text { sure, MPa }\end{array}$ & $\begin{array}{l}\text { Recovery } \\
\text { degree, } \%\end{array}$ & Water cut, $\%$ \\
\hline 0.1 & Formation water & 0.38 & 12.96 & 0.00 \\
\hline 0.2 & & 0.37 & 22.29 & 14.40 \\
\hline 0.3 & & 0.37 & 27.78 & 29.66 \\
\hline 0.4 & & 0.37 & 31.56 & 47.54 \\
\hline 0.5 & & 0.35 & 34.19 & 66.12 \\
\hline 0.6 & & 0.35 & 36.14 & 78.13 \\
\hline 0.7 & & 0.31 & 37.41 & 85.59 \\
\hline 0.8 & & 0.38 & 38.32 & 89.47 \\
\hline 0.9 & & 0.35 & 39.08 & 91.15 \\
\hline 1.0 & & 0.28 & 39.71 & 92.67 \\
\hline 1.1 & & 0.35 & 40.22 & 94.42 \\
\hline 1.2 & & 0.31 & 40.59 & 95.70 \\
\hline 1.3 & & 0.33 & 40.81 & 97.43 \\
\hline 1.4 & & 0.37 & 40.94 & 96.99 \\
\hline 1.5 & & 0.33 & 41.03 & 98.21 \\
\hline 1.6 & & 0.31 & 41.05 & 99.48 \\
\hline 1.7 & Foam & 0.27 & 41.65 & 91.52 \\
\hline 1.8 & Nitrogen & 0.29 & 41.80 & 86.67 \\
\hline 1.9 & Foam & 0.27 & 42.25 & 94.67 \\
\hline 2.0 & Nitrogen & 0.46 & 42.35 & 90.91 \\
\hline 2.1 & Foam & 0.27 & 42.60 & 95.94 \\
\hline 2.2 & Nitrogen & 0.34 & 42.68 & 94.59 \\
\hline 2.3 & Foam & 0.35 & 42.80 & 98.13 \\
\hline 2.4 & Nitrogen & 0.35 & 42.84 & 97.39 \\
\hline 2.5 & Foam & 0.37 & 42.89 & 99.28 \\
\hline
\end{tabular}

\section{Experimental result}

\section{The Guantao reservoir active water displacement experiment}

The physical model of the active water displacement experiment of the Guantao reservoir is shown in Fig. 3. The total volume of the experimental rock plate is $3600 \mathrm{~mL}$, the pore volume is $1200 \mathrm{~mL}$, the hydrocarbon pore volume is $800 \mathrm{~mL}$, and the irreducible water saturation is $33 \%$. In the water drive stage, the bottom water is injected at a constant rate from the bottom of the reservoir for displacement, and the displacement rate is $5 \mathrm{~mL} / \mathrm{min}$. In the active water drive stage, the active water is injected from the A well at a constant rate of $5 \mathrm{~mL} / \mathrm{min}$. The experimental displacement data are shown in Table 5. The variation curves of water cut, cumulative recovery degree, cumulative oil production, and differential pressure with cumulative injected hydrocarbon pore volume during displacement are shown in Fig. 6. The displacement process scanned by X-CT in the experiment is shown in Fig. 7.

When 1.5HCPV is injected accumulatively, the water cut of the B well reaches $99 \%$, and the water drive ends. The recovery degree in the water drive stage is $42.03 \%$. The $A$ well is injected with active water, and the B well is used as a production. At the initial stage of active water injection, the water cut of the B well decreases to $93.3 \%$. When the cumulative injection of 1.9HCPV, the water cut of the B well reaches $99 \%$, and the active water drive ends. The increased recovery degree in the active water drive stage is $0.73 \%$.

In the bottom water drive stage, the bottom water advances upward as a whole without forming a water cone, as shown in Fig. 7. In the later stage of the water drive stage, a small water cone is formed around the near well zone, but the water cone phenomenon is not apparent, and the amount of remaining oil between wells is small. In the stage of active water flooding, the change of production differential 


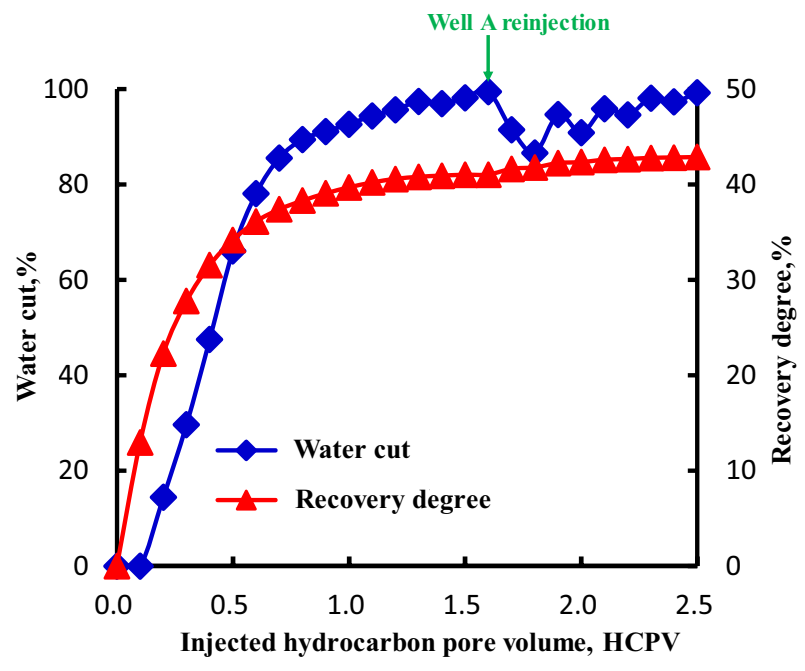

(a) Water cut and cumulativerecovery vary with the pore volume of injected hydrocarbons

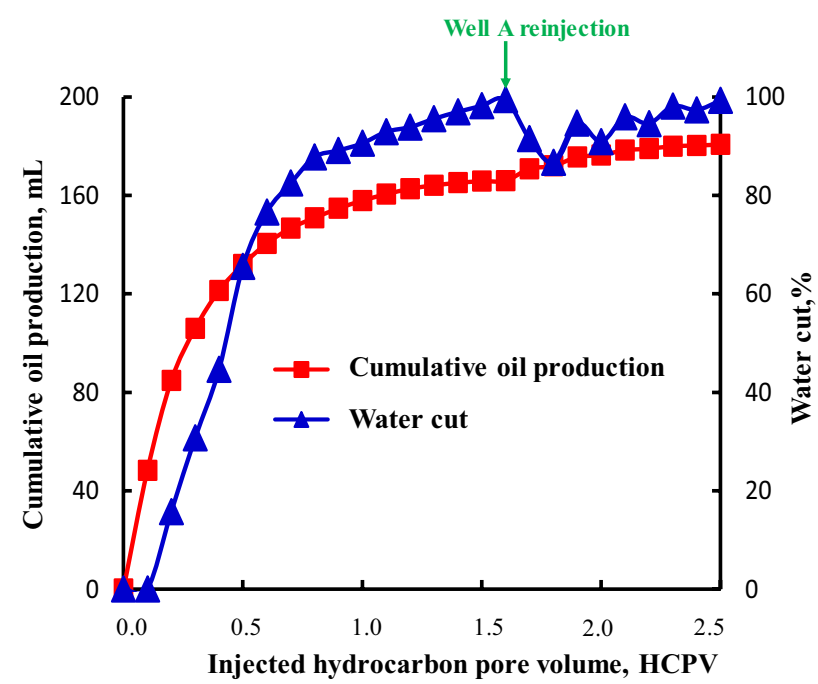

(c) The cumulative oil production and water cut of theB well vary with the pore volume of injected hydrocarbons

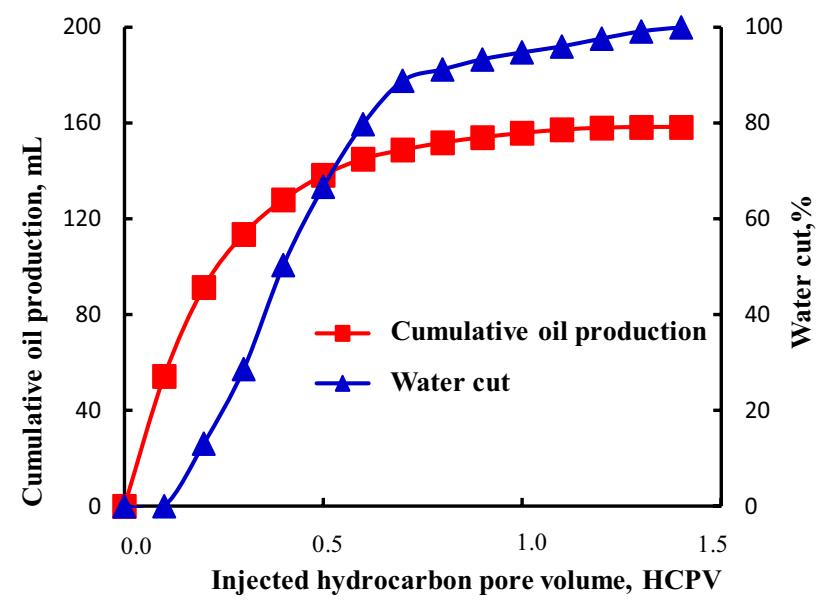

(b) The cumulative oil production and water cut of the A well vary with the pore volume of injected hydrocarbons

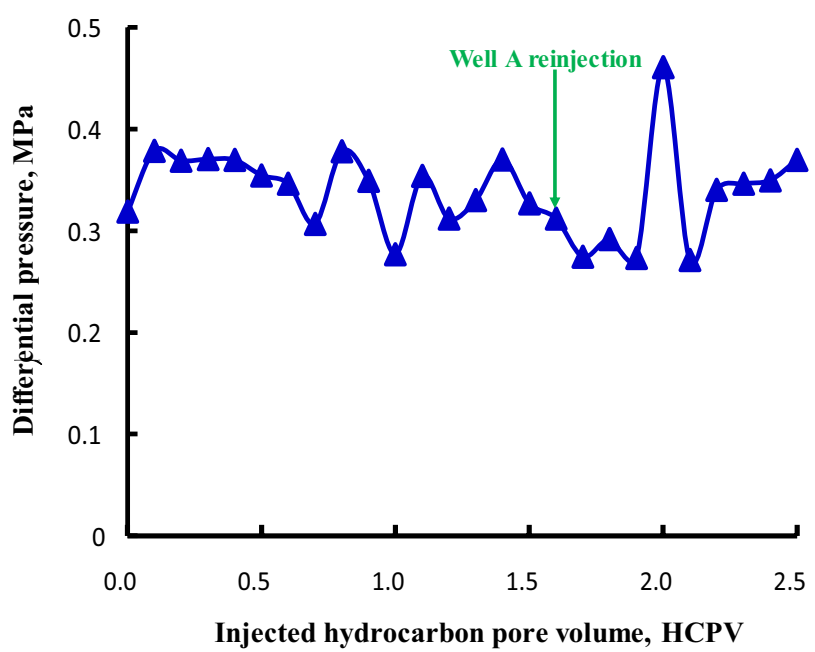

(d) Variation of production differential pressure with a pore volume of injected hydrocarbon

Fig. 8 Dynamic data change of gas foam alternate displacement in the Guantao reservoir

pressure generally shows a decreasing trend, indicating that the active water injection mainly flows along the high waterbearing zone, and the plane displacement is not significant. Due to the good physical properties of the Guantao reservoir simulated strata and the low viscosity of simulated oil, the recovery degree in the bottom water drive stage is high, and the amount of residual oil between wells is small, resulting in the low recovery degree of active water drive. After the active water drive end, residual oil enrichment is at the top of the reservoir.

\section{Experiment of gas foam alternating flooding in the Guantao reservoir}

The second set is the alternate gas foam flooding experiment of the Guantao reservoir, and the physical model is shown in Fig. 3. The total volume of the experimental rock plate is $3600 \mathrm{~mL}$, the pore volume is $1200 \mathrm{~mL}$, the hydrocarbon pore volume is $790 \mathrm{~mL}$, and the irreducible water saturation is $34 \%$. In the water flooding stage, the bottom water is injected at a constant speed from the bottom of the reservoir, and the 


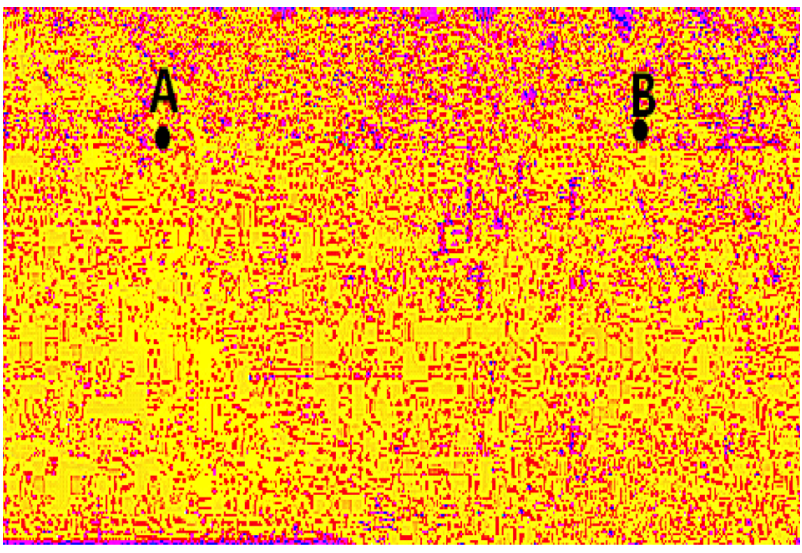

(a) Original rock sample

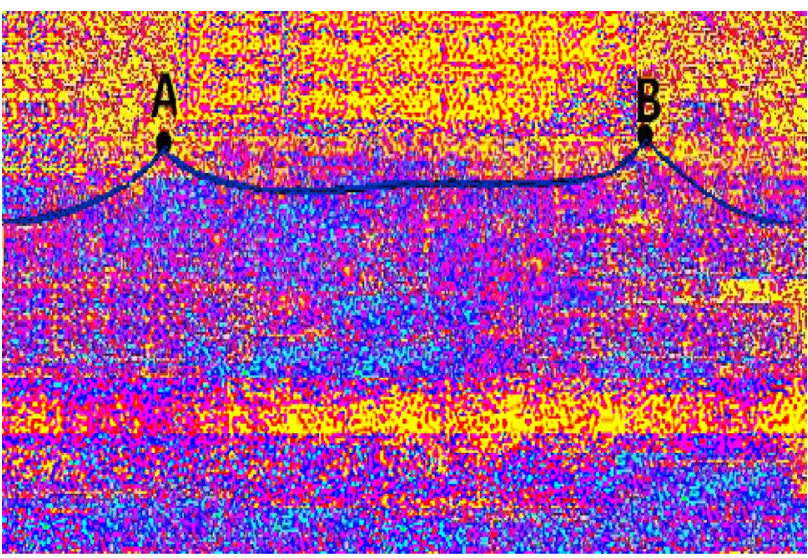

(b) End of water flooding

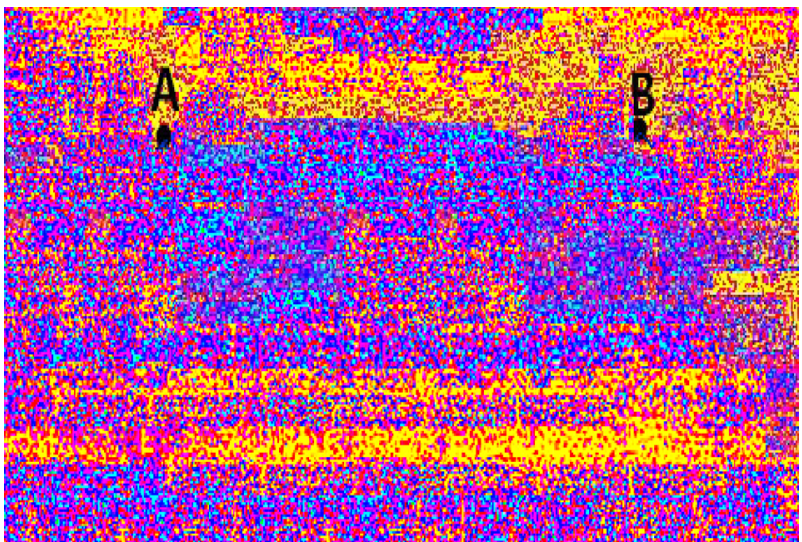

(c) End of gas foam alternate flooding

Fig. 9 Alternate displacement process of sand gas in the Guantao reservoir

displacement rate is $5 \mathrm{~mL} / \mathrm{min}$ : gas and foam alternate drive stage. The gas and foam alternately infuse $0.1 \mathrm{HCPV}$ from the A well at a constant speed, and the injection rate is $5 \mathrm{~mL} / \mathrm{min}$. The experimental displacement data are shown in Table 6. The variation curves of water cut, cumulative recovery degree, cumulative oil production, and differential pressure with cumulative injected hydrocarbon pore volume during displacement are shown in Fig. 8. The displacement process scanned by X-CT in the experiment is shown in Fig. 9.

When 1.6HCPV is injected accumulatively, the water cut of the B well reaches $99 \%$, and the water drive ends. The cumulative recovery degree in the water drive stage is $41.05 \%$. A well alternately injects $0.1 \mathrm{HCPV}$ gas and foam, the B well as a production well. When $1.8 \mathrm{HCPV}$ was injected accumulatively, the water cut of the B well decreased to $86.67 \%$. When accumulating $2.5 \mathrm{HCPV}$, the water cut of the B well reaches $99 \%$, and the gas and foam alternate drive ends. The cumulative recovery of gas and foam in the alternate flooding stage is $1.84 \%$.

In the bottom water drive stage, the bottom water pushes upward as a whole without forming a water cone, as shown in Fig. 9. In the later stage of the water drive stage, a small water cone is formed around the near well zone, but the water cone phenomenon is not apparent. During the alternate gas and foam flooding stage, the production pressure difference first decreased and then increased. After injection of $0.2 \mathrm{HCPV}$ foam, the pressure difference was as high as $0.46 \mathrm{MPa}$, indicating that foam injection played a specific role in profile control. The nitrogen foam floods through the formation of top gas drive, plane water drive, and inter-well residual oil use. Generally speaking, the Guantao reservoir has good physical properties, low oil viscosity, high recovery level in the bottom water drive stage, resulting in a low absolute value of nitrogen foam flooding.

\section{Gas foam alternate flooding experiment of the 943 reservoir}

The third set of the 943 reservoir alternate gas foam flooding experiment shows the physical model in Fig. 3. In the experiment, if the total volume of the plate is $3600 \mathrm{~mL}$, the pore volume is $830 \mathrm{~mL}$, the pore volume of hydrocarbons is $660 \mathrm{~mL}$, and the irreducible water saturation is $20 \%$. In the water drive stage, the bottom water is injected at a constant rate from the bottom of the reservoir for displacement, and the displacement rate is $5 \mathrm{~mL} / \mathrm{min}$. The gas and foam alternately drive the gas and foam from A well to $0.1 \mathrm{HCPV}$ at a constant speed, and the injection rate is $5 \mathrm{~mL} / \mathrm{min}$. The experimental displacement data are shown in Table 7. The variation curves of water cut, cumulative recovery degree, cumulative oil production, and differential pressure with cumulative injected hydrocarbon pore volume during displacement are shown in Fig. 10. The displacement process scanned by $\mathrm{X}-\mathrm{CT}$ in the experiment is shown in Fig. 11. 
Table 7 The gas and foam alternate flooding data of the 943 reservoir

\begin{tabular}{|c|c|c|c|c|}
\hline $\begin{array}{l}\text { Injected hydrocarbon pore } \\
\text { volume, HCPV }\end{array}$ & Injection medium & $\begin{array}{l}\text { Differential pres- } \\
\text { sure, MPa }\end{array}$ & $\begin{array}{l}\text { Recovery } \\
\text { degree, } \%\end{array}$ & Water cut, $\%$ \\
\hline 0.1 & Formation water & 0.32 & 8.11 & 0.00 \\
\hline 0.2 & & 0.38 & 10.76 & 65.69 \\
\hline 0.3 & & 0.37 & 12.32 & 84.96 \\
\hline 0.4 & & 0.37 & 13.44 & 88.12 \\
\hline 0.5 & & 0.37 & 14.50 & 90.28 \\
\hline 0.6 & & 0.37 & 15.44 & 91.74 \\
\hline 0.7 & & 0.35 & 16.21 & 93.84 \\
\hline 0.8 & & 0.35 & 16.64 & 96.23 \\
\hline 0.9 & & 0.31 & 17.52 & 90.69 \\
\hline 1.0 & & 0.38 & 18.30 & 91.19 \\
\hline 11 & & 0.35 & 19.14 & 91.4592 .87 \\
\hline 1.2 & & 0.28 & 19.83 & \\
\hline 1.3 & & 0.35 & 20.35 & 94.63 \\
\hline 1.4 & & 0.31 & 20.62 & 97.38 \\
\hline 1.5 & & 0.37 & 20.70 & 99.21 \\
\hline 1.6 & Foam & 0.33 & 21.18 & 95.41 \\
\hline 1.7 & Nitrogen & 0.31 & 21.26 & 93.51 \\
\hline 1.8 & Foam & 0.27 & 22.74 & 81.04 \\
\hline 1.9 & Nitrogen & 0.29 & 23.26 & 83.33 \\
\hline 2.0 & Foam & 0.35 & 24.36 & 84.47 \\
\hline 2.1 & Nitrogen & 0.37 & 24.82 & 87.70 \\
\hline 2.2 & Foam & 0.37 & 25.58 & 81.95 \\
\hline 2.3 & Nitrogen & 0.35 & 26.52 & 72.07 \\
\hline 2.4 & Foam & 0.37 & 27.95 & 74.32 \\
\hline 2.5 & Nitrogen & 0.37 & 29.17 & 75.38 \\
\hline 2.6 & Foam & 0.35 & 30.86 & 78.79 \\
\hline 2.7 & Nitrogen & 0.38 & 32.06 & 82.21 \\
\hline 2.8 & Foam & 0.31 & 32.52 & 90.96 \\
\hline 2.9 & Nitrogen & 0.35 & 32.70 & 92.59 \\
\hline 3.0 & Foam & 0.28 & 32.97 & 95.00 \\
\hline 3.1 & Nitrogen & 0.35 & 33.09 & 95.24 \\
\hline 3.2 & Foam & 0.31 & 33.14 & 99.17 \\
\hline
\end{tabular}

When 1.0HCPV is injected accumulatively, the water cut of A well reaches $99 \%$, and the water drive ends. The cumulative recovery degree in the water drive stage is $20.07 \%$. The A well alternately injects $0.1 \mathrm{HCPV}$ gas and foam and the $\mathrm{B}$ well as production. At the initial stage of nitrogen foam flooding, the water cut of The B well dropped to $72.07 \%$. When cumulative injection of 3.2HCPV, the water cut of The B well reached $99 \%$, and the gas and foam alternate drive ended. The cumulative recovery of gas and foam in alternate flooding stages is $12.44 \%$.
There is a well-known water cone phenomenon in the bottom water drive stage due to the excessive oil-water viscosity ratio, as shown in Fig. 11. After water channeling, the bottom water directly enters the production well along the formed water channel, the water cut rises rapidly, and the water drive sweep volume is small, resulting in a low recovery degree of water drive. In the alternate gas and foam flooding stage, the injected foam forms an effective plugging into the simulated reservoir and improves the production pressure difference. Under the action of gravity and foam profile control, the 


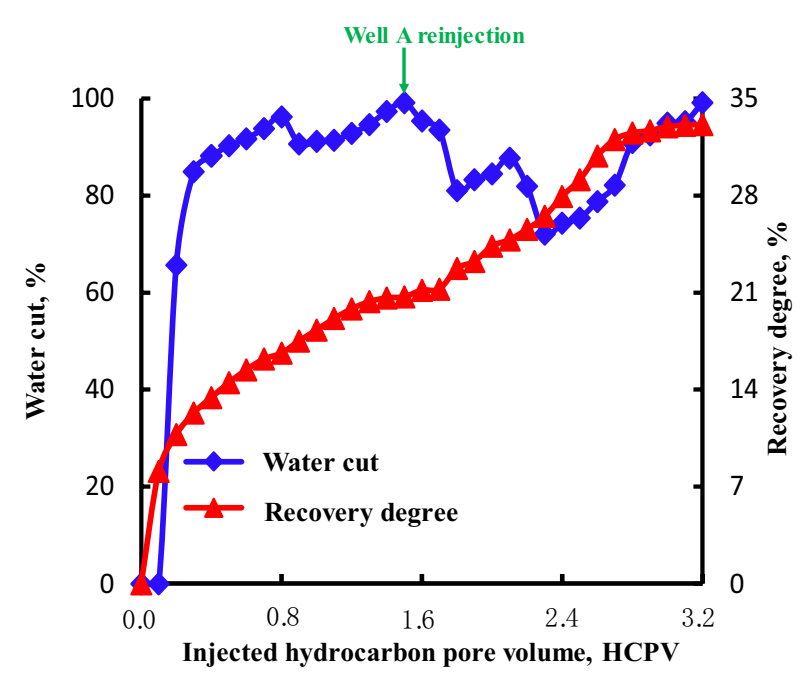

(a) Water cut and cumulative recovery vary with the pore volume of injected hydrocarbons

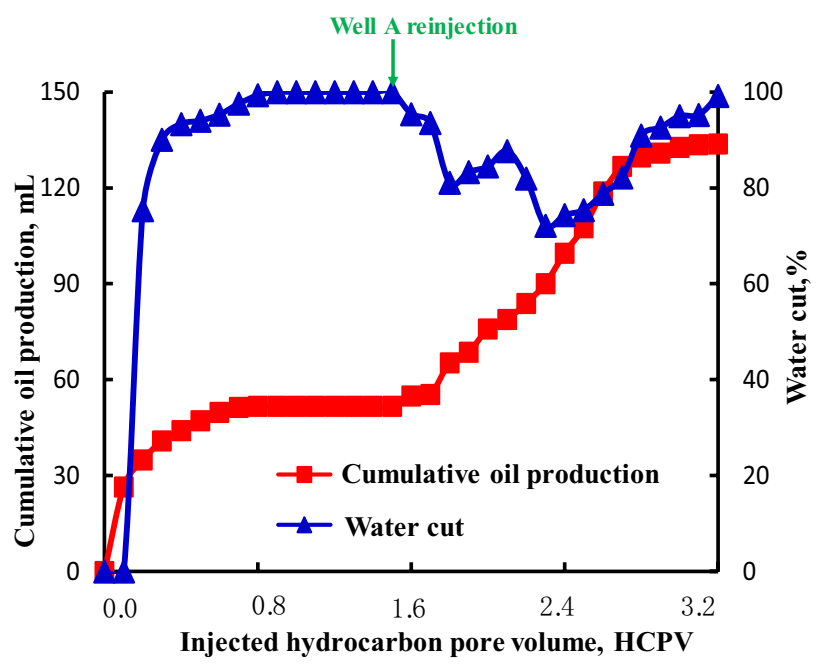

(c) The cumulative oil production and water cut of the B well vary with the pore volume of injected hydrocarbons

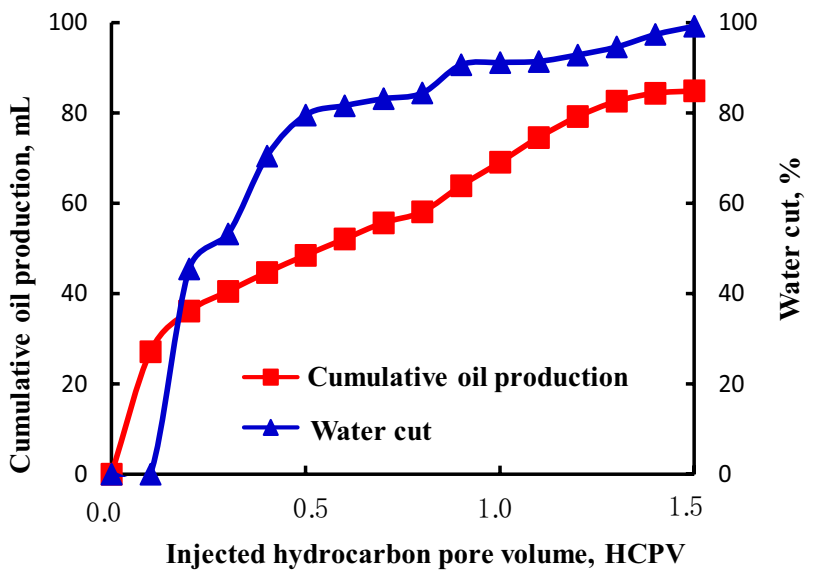

(b) The cumulative oil production and water cut of the A well vary with the pore volume of injected hydrocarbons

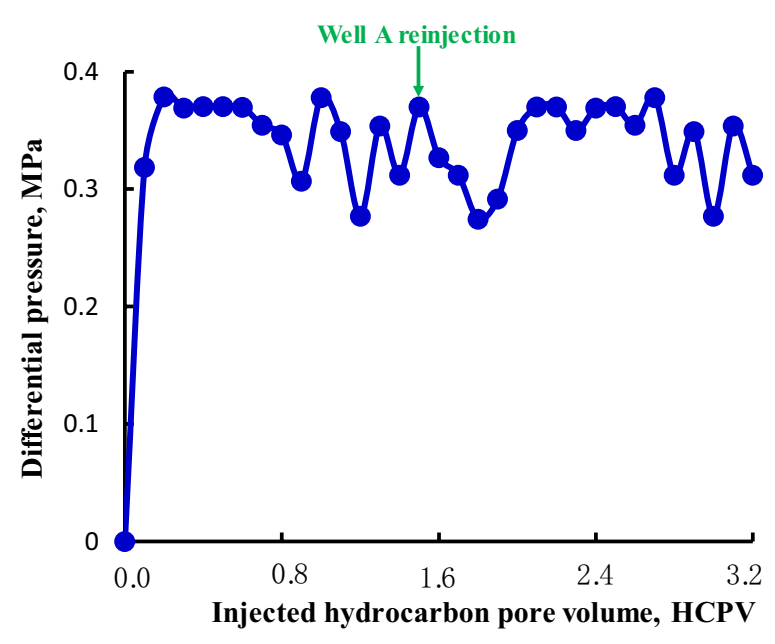

(d) Variation of production differential pressure with a pore volume of injected hydrocarbon

Fig. 10 Dynamic data change of gas foam alternate displacement in the 943 reservoir

injected gas forms a small gas cap at the top of the simulated reservoir to drive the remaining oil from the top of the well down to replace. Due to the high viscosity of the simulated oil and the low permeability of the upper reservoir, the phenomenon of gas channeling is relatively high.

On the other hand, the active components in the injected foaming agent reduce the oil-water interfacial tension and improve the oil washing ability of the injected solution. Gas and foam alternately drive up the reservoir volume and the oil washing capacity of the injected liquid, which significantly improves the utilization degree of the remaining oil between the wells. After the gas and foam alternate drive, there is still a large amount of remaining oil between the reservoir edge and the well.

\section{Summary}

According to the experiment in this section, because of the good physical properties and low viscosity of simulated oil in the Guantao reservoir, the recovery level in the bottom water drive stage is high, and the residual oil in the wells is few. The degree of recovery from active water flooding and nitrogen foam flooding is not high, only $0.73 \%$ and $1.84 \%$ (see Table 8 ). Nitrogen foam flooding is better than active water flooding. After the end of the active water drive and nitrogen foam flooding, the remaining oil is enriched at the top of the reservoir.

The 943 reservoir cumulative recovery of gas and foam in the alternate flooding stage is $12.44 \%$ (see Table 8 ). The main reason is that when the gas and foam alternate 


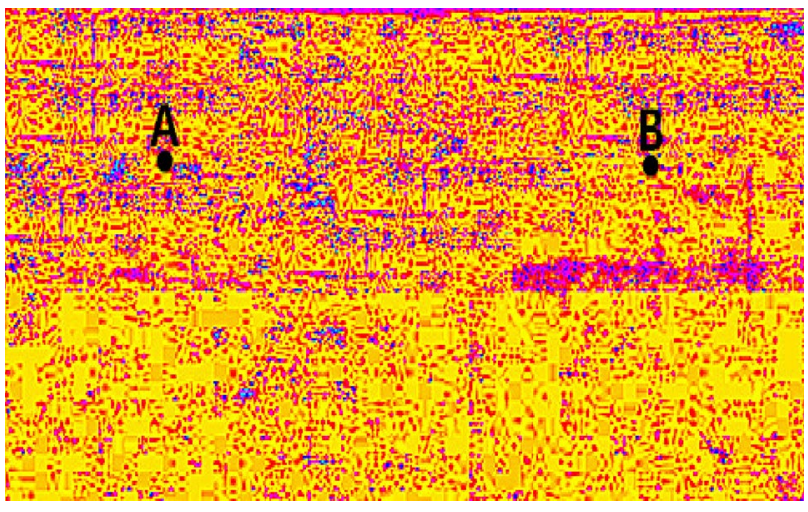

(a) Original rock sample

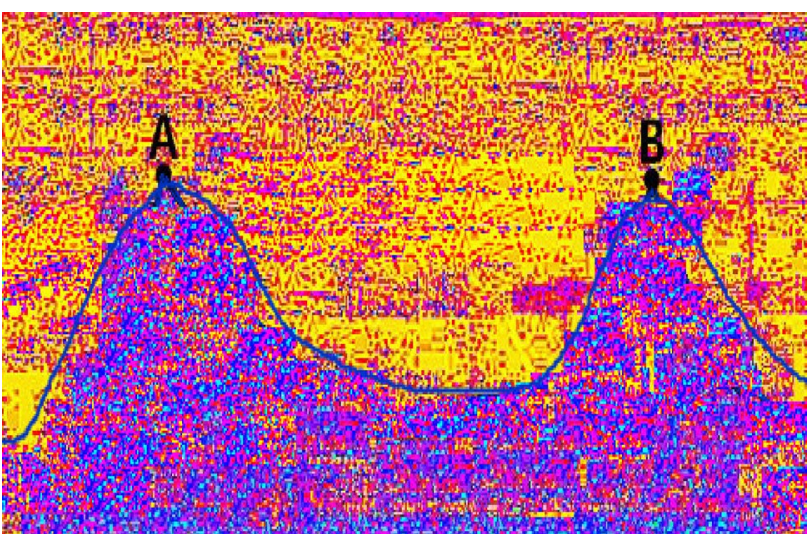

(b) End of water flooding

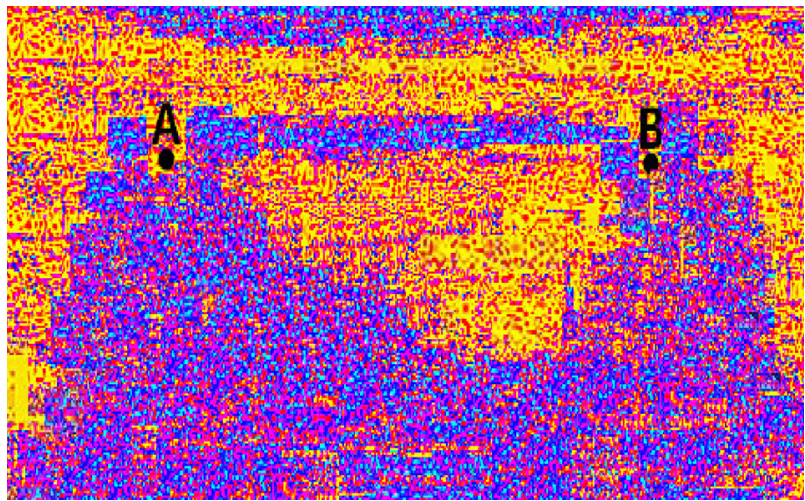

(c) End of gas foam alternate flooding

Fig. 11 Alternate gas foam flooding process of the 943 reservoir flooding stage, the injected foam forms an effective plugging into the simulated reservoir and improves the production pressure difference. On the other hand, the active components in the injected foaming agent reduce the oil-water interfacial tension and improve the oil washing ability of the injected solution. Gas and foam alternately drive up the reservoir volume and the oil washing capacity of the injected liquid, which significantly improves the utilization degree of the remaining oil between the wells. After the gas and foam alternate drive, there is still a large amount of remaining oil at the reservoir's edge between the wells and the top.

\section{Physical simulation of top residual oil displacement production}

\section{Establishment of a physical model of rock slab}

Three horizontal wells (the A, B, and C well) and bottom water-screen are designed according to the manufacturing process of the cross well-remaining oil the Guantao and 943 reservoirs if plate and the actual well group. The reservoir thickness in the upper part of the 943 reservoir experimental rock plate is $7 \mathrm{~cm}$, and the permeability is $500 \mathrm{mD}$. The thickness of the middle reservoir is $20 \mathrm{~cm}$, and the permeability is $2500 \mathrm{mD}$. The thickness of the lower reservoir is $3 \mathrm{~cm}$, and the permeability is $500 \mathrm{mD}$. The A Well is in the middle of the upper reservoir, the $B$ well is in the middle of the middle reservoir, and the $\mathrm{C}$ well is in the middle of the lower reservoir. The simulated length of all horizontal wells is $25 \mathrm{~cm}$, located in the middle of each reservoir, as shown in Fig. 12a. Based on this well pattern design, a new injection of the D well is added, located at the upper right of the rock plate, and the well diameter is $2 \mathrm{~mm}$, as shown in Fig. 12b.

\section{Experimental scheme and process}

The physical simulation experiment temperature of interwell residual oil displacement production is $20{ }^{\circ} \mathrm{C}$, the experimental pressure is $3 \mathrm{MPa}$, and the experimental instrument is an ANERX-CT-K6550 scanner. Three groups
Table 8 Physical simulation experiment results of interwell residual oil displacement production

\begin{tabular}{lll}
\hline Displacement mode & Injection medium & $\begin{array}{l}\text { Recovery } \\
\text { degree, } \%\end{array}$ \\
\hline The Guantao reservoir active water flooding & Formation water & 42.03 \\
& Active water & 42.76 \\
The gas and foam alternate flooding data of the Guantao reservoir & Formation water & 41.05 \\
& Gas foam alternate & 42.89 \\
The gas and foam alternate flooding data of the 943 reservoir & Formation water & 20.7 \\
& Gas foam alternate & 33.14 \\
\hline
\end{tabular}


Fig. 12 The well location of the 943 reservoir

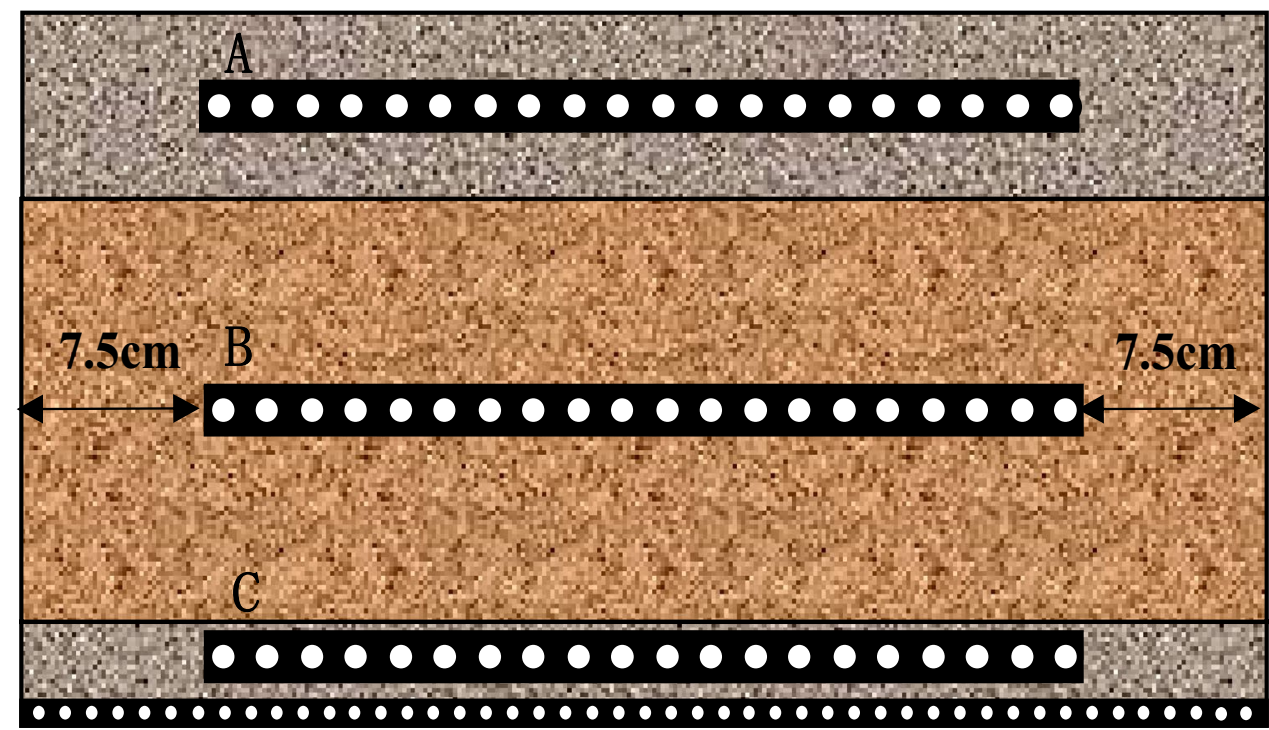

(a) Original well pattern of the 943 reservoir

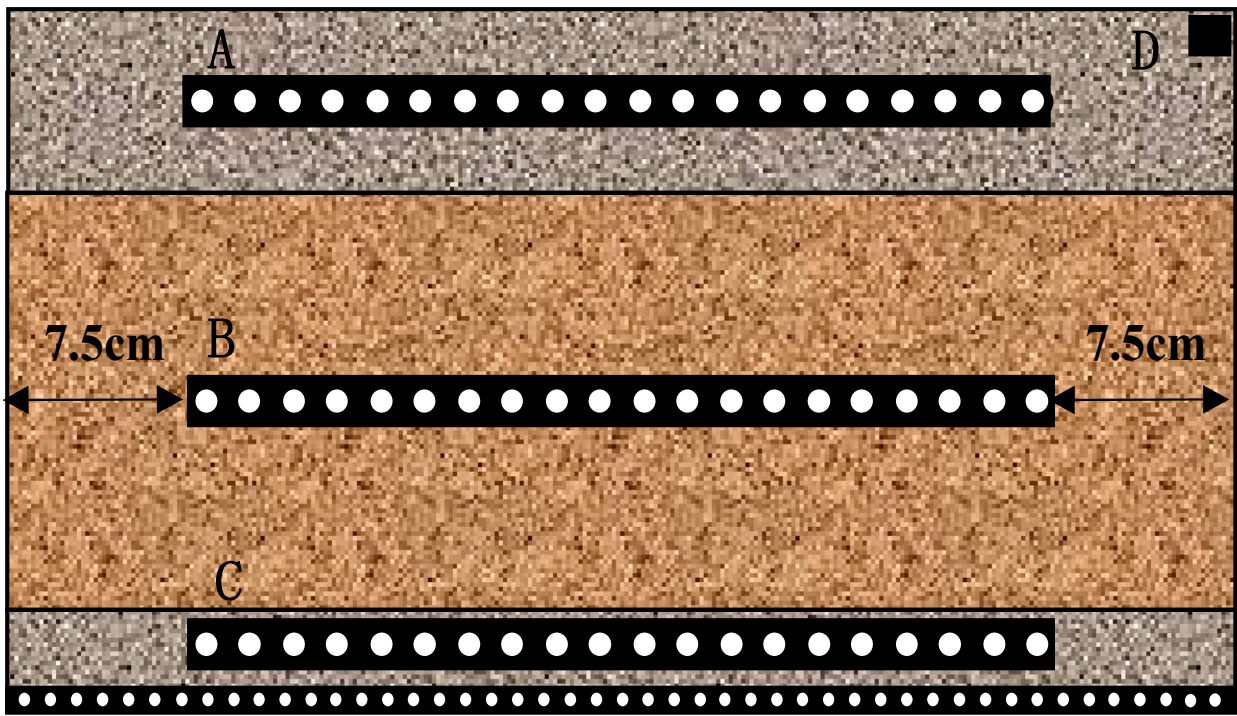

(b) New well pattern of the 943 reservoir of experiments are designed. The first group of the 943 reservoir original well active water displacement experiment, second group the 943 reservoir-new well active water displacement experiment, third group the 943 reservoir original well alternate gas foam flooding experiment, the plan is as follows.

The first group of experiments: the rock plate is made according to the original well layout of the 943 reservoir. Inject the 943 reservoir formation water constant $\left(\mathrm{V}_{1} \mathrm{~mL} /\right.$ min) from the bottom water inlet for displacement. Record the pressure, outlet pressure, confining pressure, oil, and water produced and produced by each well for each injection of $0.1 \mathrm{HCPV}$, and send the experimental rock plate into the X-ray machine for scanning: calculate the water cut of each well. When the water cut of a well reaches more than $99 \%$, close the well to continue production; until the production wells are closed, the water drive is over. Select the A well as the injection well in the active water drive section, inject the active water drive and record the data. When the water cut of the production well reaches more than $99 \%$, close the well until all production wells are closed and production is stopped. 
Table 9 Oil displacement data of active water injected into original wells of the 943 reservoir

\begin{tabular}{|c|c|c|c|c|}
\hline $\begin{array}{l}\text { Injected hydrocarbon pore } \\
\text { volume, HCPV }\end{array}$ & Injection medium & $\begin{array}{l}\text { Differential pres- } \\
\text { sure, } \mathrm{MPa}\end{array}$ & $\begin{array}{l}\text { Recovery } \\
\text { degree, } \%\end{array}$ & Water cut, $\%$ \\
\hline 0.1 & \multirow[t]{15}{*}{ Formation water } & 0.32 & 12.99 & 28.18 \\
\hline 0.2 & & 0.38 & 14.24 & 88.03 \\
\hline 0.3 & & 0.37 & 14.90 & 93.42 \\
\hline 0.4 & & 0.37 & 17.16 & 64.89 \\
\hline 0.5 & & 0.37 & 19.49 & 75.75 \\
\hline 0.6 & & 0.35 & 20.92 & 85.02 \\
\hline 0.7 & & 0.35 & 22.21 & 87.52 \\
\hline 0.8 & & 0.31 & 23.03 & 91.66 \\
\hline 0.9 & & 0.38 & 23.53 & 94.91 \\
\hline 1.0 & & 0.35 & 25.31 & 67.01 \\
\hline 1.1 & & 0.28 & 27.30 & 80.56 \\
\hline 1.2 & & 0.35 & 28.56 & 88.05 \\
\hline 1.3 & & 0.31 & 29.46 & 91.41 \\
\hline 1.4 & & 0.33 & 29.76 & 96.65 \\
\hline 1.5 & & 0.33 & 29.85 & 99.08 \\
\hline 1.6 & \multirow[t]{8}{*}{ Active water } & 0.33 & 30.33 & 95.21 \\
\hline 1.7 & & 0.31 & 31.11 & 91.86 \\
\hline 1.8 & & 0.32 & 31.80 & 93.74 \\
\hline 1.9 & & 0.31 & 32.24 & 95.72 \\
\hline 2.0 & & 0.30 & 32.34 & 98.99 \\
\hline 2.1 & & 0.32 & 32.54 & 97.54 \\
\hline 2.2 & & 0.31 & 32.68 & 98.40 \\
\hline 2.3 & & 0.32 & 32.76 & 99.12 \\
\hline
\end{tabular}

The second group of experiments: make a new rock plate according to the new well layout of the 943 reservoir. Inject the 943 reservoir formation water constant $\left(\mathrm{V}_{1} \mathrm{~mL} /\right.$ min) from the bottom water inlet for displacement. Record the inlet pressure, outlet pressure, confining pressure, and the oil and water output of production wells a, B, and C for each injection of $0.1 \mathrm{HCPV}$, and send the experimental rock plate into the $\mathrm{X}$-ray machine for scanning: calculate the water cut of each well. When the water cut of A well reaches more than $99 \%$, close the well to continue production; until the production wells are closed, the water drive is over. In the active water drive stage, the D well is selected as the injection, the active water drive is used, and the data are recorded. When the production content well reaches more than $99 \%$, the production is shut down until all production is shut down and the production is stopped.

The third group of experiments: to eliminate the experimental error, a new rock plate was made according to the original well layout of the 943 reservoir seconds. The formation water of the 943 reservoir is injected at a constant rate $\left(\mathrm{V}_{1} \mathrm{~mL} / \mathrm{min}\right)$ from the bottom water population end for displacement. For each injection of $0.1 \mathrm{HCPV}$, the inlet pressure, confining pressure, and the oil, water, and gas output of each production well are recorded, and the experimental rock plate is sent to the X-ray machine for scanning: calculate the water cut of each well. When the water cut of A well reaches more than $99 \%$, close the well to continue production until the production wells are closed, end of water drive. In the active water drive stage, A well is selected as the injection well, and the $0.1 \mathrm{HCPV}$ gas and foam alternately drive are alternately injected and recorded data. When the water cut of the production well reaches more than $99 \%$, the production well is closed until all production is closed and production is stopped. The experimental process is as follows(see Fig. 5):

\section{(1) Prepare oil samples and instruments.}

Prepare the rock plate holder, put the rock plate into the rock plate holder according to the requirements, calibrate various instruments, clean and blow-dry, pressure test, vacuum, and keep it to the experimental value. 

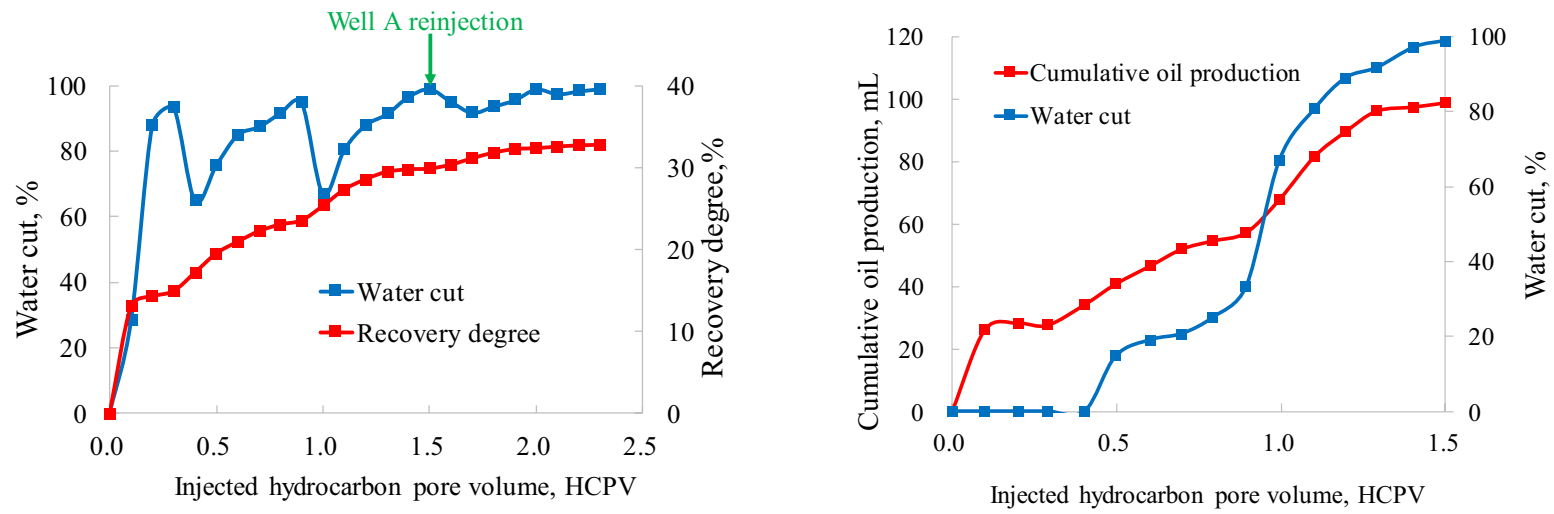

(a) Water cut and cumulative recovery vary with the pore volume of injected hydrocarbons

(b) The cumulative oil production and water cut of the A well vary with the pore volume of injected hydrocarbons

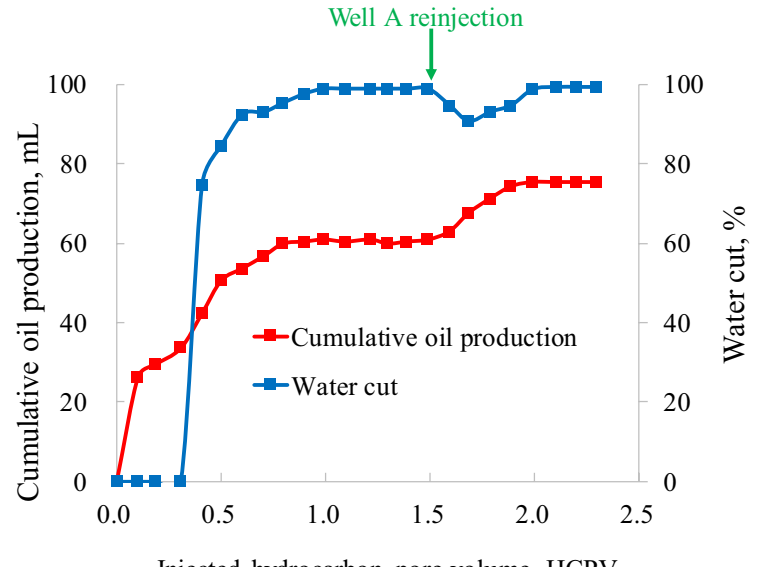

Injected hydrocarbon pore volume, HCPV

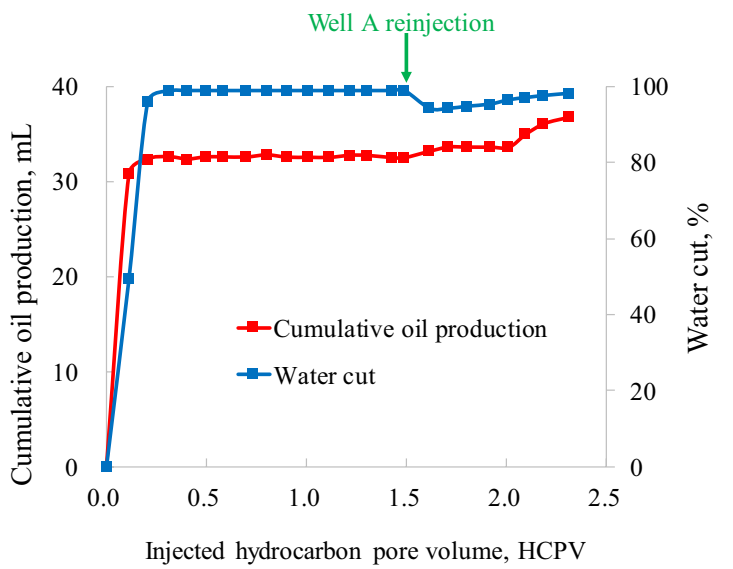

(c) The cumulative oil production and water cut of the $B$ well vary with the pore volume of injected hydrocarbons

(d) The cumulative oil production and water cut of the $\mathrm{C}$ well vary with the pore volume of injected hydrocarbons

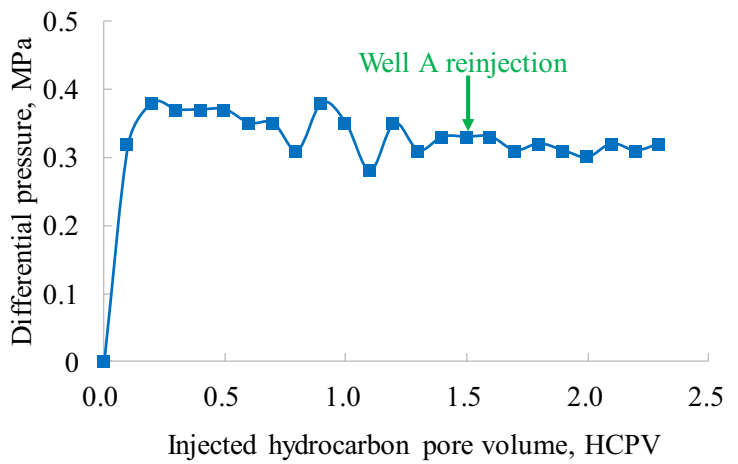

(e) Variation of production differential pressure with a pore volume of injected hydrocarbon

Fig.13 Dynamic data change of active water displacement process in the original well of the 943 reservoir

\section{(2) Establish bound water}

After vacuuming the rock plate, saturate the formation water at constant pressure, establish a water beam after oil displacement, and record the injected water volume and water output in this process.

\section{(3) Saturation of oil sample}

Establish the system pressure and use the prepared oil sample to displace several times the pore volume. When the composition of the oil sample at the outlet is the same 


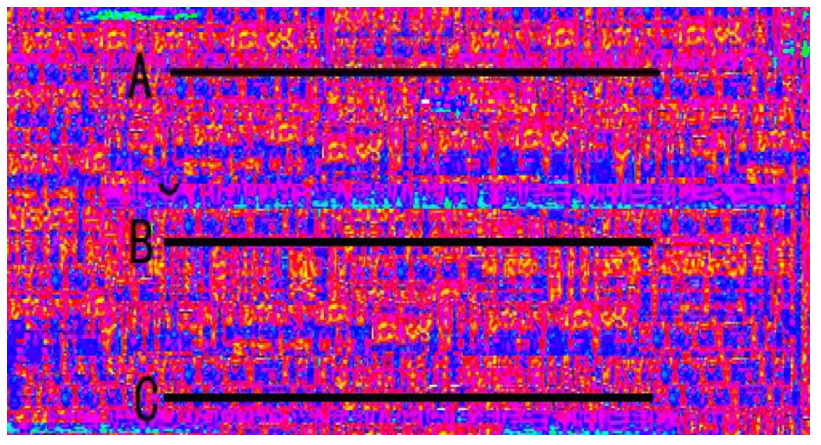

(a) Original rock sample

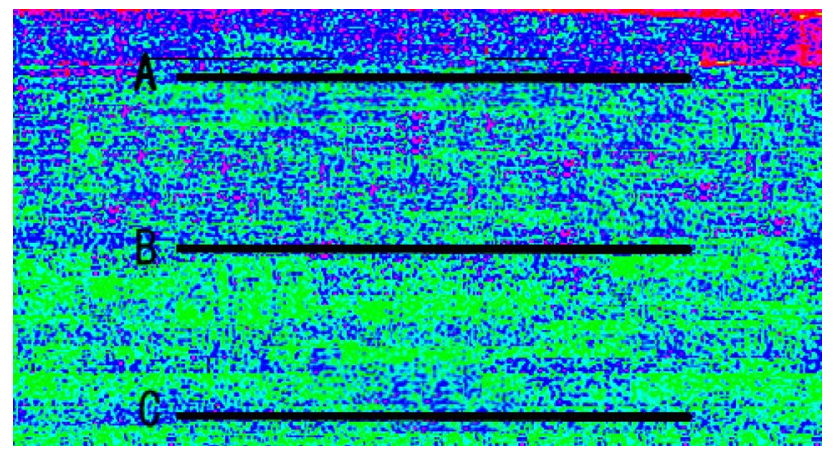

(b) End of water flooding

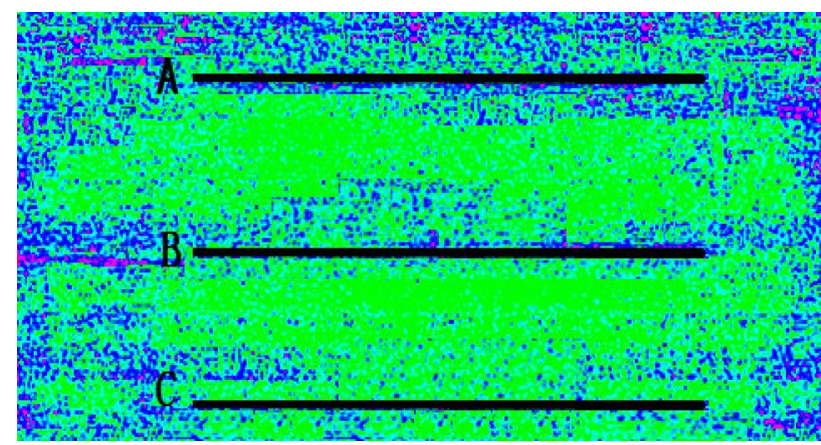

(c) End of active water flooding

Fig. 14 Active water displacement process in the original well of the 943 reservoir

as that of the displaced oil sample, the sample is saturated and forms the original state.

\section{(4) Experiment}

According to the scheme design, different single-phase fluid continuous displacement experiments are carried out after the sample is saturated.

\section{Active water displacement experiment in the original well of the 943 reservoir}

See Fig. 11a for the physical model of the first group of the 943 reservoir original well active water displacement experiment. The total volume of the experimental rock plate is $3600 \mathrm{~mL}$, the pore volume is $810 \mathrm{~mL}$, the pore volume of hydrocarbons is $650 \mathrm{~mL}$, and the irreducible water saturation is $20 \%$. In the water drive stage, the bottom water is injected at a constant rate from the bottom of the reservoir for displacement, with a displacement rate of $5 \mathrm{~mL} / \mathrm{min}$; in the active water drive stage, active water is injected at a constant rate from the A well, with an injection rate of $5 \mathrm{~mL} / \mathrm{min}$. The experimental displacement data are shown in Table 9. The variation curves of water cut, cumulative recovery degree, cumulative oil production, and differential pressure with cumulative injected hydrocarbon pore volume during displacement are shown in Fig. 13. The displacement process scanned by X-CT in the experiment is shown in Fig. 14.

When $1.5 \mathrm{HCPV}$ is injected accumulatively, the A well of production well is completely flooded, and the A well is closed. The cumulative oil production of the A well is $97.96 \mathrm{~mL}$. The water drive stage is completed, and the final recovery degree is $29.85 \%$. Active water is injected into the A well, and wells B and C are used as production wells. At the initial stage of active water injection, the total water cut decreases to $91.86 \%$. When $2.3 \mathrm{HCPV}$ is injected accumulatively, the $\mathrm{C}$ well is completely flooded, the $\mathrm{C}$ well is closed, water flooding is completed, and the active water drive stage is recovered $2.91 \%$.

In the bottom water drive stage, the water breakthrough in the middle and upper wells is slow, the recovery degree is high, $24.73 \%$, and the contribution rate is $82.87 \%$. Due to the large control area of horizontal wells, there is no characteristic of bottom water ridging, the oil-water interface advances upward evenly, and the recovery degree is high in the water drive stage. In the active water flooding stage, the production differential pressure drops to $0.33 \mathrm{MPa}$, which shows that after the active water injected from the A well enters the simulated reservoir, it mainly flows along the high water-bearing zone, and the spread range has not been improved. However, the vertical displacement effect is noticeable; the remaining oil in the upper part of the middle horizontal section can be used, and the remaining oil in the upper part of the top horizontal section cannot be used, as shown in Fig. 14.

\section{Experimental result}

\section{Active water displacement experiment in the new well of the 943 reservoir}

The second group is a new well active water displacement experiment of the 943 reservoir. The physical model is shown in Fig. 12b. The total volume of the experimental rock plate is $3600 \mathrm{~mL}$, the pore volume is $805 \mathrm{~mL}$, the hydrocarbon pore volume is $640 \mathrm{~mL}$, and the water saturation is $21 \%$. In the water drive stage, the bottom water is

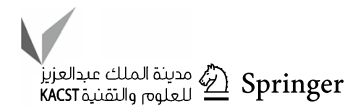


Table 10 Oil displacement data of active water injected into new wells of the 943 reservoir

\begin{tabular}{|c|c|c|c|c|}
\hline $\begin{array}{l}\text { Injected hydrocarbon pore } \\
\text { volume, HCPV }\end{array}$ & Injection medium & $\begin{array}{l}\text { Differential pres- } \\
\text { sure, } \mathrm{MPa}\end{array}$ & $\begin{array}{l}\text { Recovery } \\
\text { degree, } \%\end{array}$ & Water cut, $\%$ \\
\hline 0.1 & \multirow[t]{12}{*}{ Formation water } & 0.32 & 6.00 & 15.45 \\
\hline 0.2 & & 0.38 & 8.84 & 43.59 \\
\hline 0.3 & & 0.37 & 10.92 & 68.61 \\
\hline 0.4 & & 0.37 & 14.92 & 33.51 \\
\hline 0.5 & & 0.37 & 18.65 & 51.98 \\
\hline 0.6 & & 0.35 & 21.48 & 65.35 \\
\hline 0.7 & & 0.35 & 24.08 & 70.02 \\
\hline 0.8 & & 0.31 & 25.79 & 80.94 \\
\hline 0.9 & & 0.38 & 27.11 & 88.47 \\
\hline 1.0 & & 0.35 & 27.89 & 86.67 \\
\hline 1.1 & & 0.28 & 28.23 & 95.94 \\
\hline 1.2 & & 0.35 & 28.31 & 99.12 \\
\hline 1.3 & \multirow[t]{7}{*}{ Active water } & 0.31 & 30.34 & 72.25 \\
\hline 1.4 & & 0.33 & 31.90 & 84.43 \\
\hline 1.5 & & 0.37 & 32.94 & 91.53 \\
\hline 1.6 & & 0.35 & 33.68 & 93.33 \\
\hline 1.7 & & 0.35 & 34.06 & 97.06 \\
\hline 1.8 & & 0.31 & 34.24 & 98.67 \\
\hline 1.9 & & 0.29 & 34.31 & 99.32 \\
\hline
\end{tabular}

injected at a constant rate from the bottom of the reservoir for displacement, and the displacement rate is $5 \mathrm{~mL} / \mathrm{min}$; in the active water drive stage, the active water is injected at a constant rate from the $\mathrm{D}$ well, and the injection rate is $5 \mathrm{~mL} / \mathrm{min}$. The experimental displacement data are shown in Table 10. The variation curves of water cut, cumulative recovery degree, cumulative oil production, and differential pressure with cumulative injected hydrocarbon pore volume during displacement are shown in Fig. 15. The displacement process scanned by XCT in the experiment is shown in Fig. 16.

When the cumulative injection of $1.2 \mathrm{HCPV}$, the production of the A well is completely flooded, the A well is closed, the cumulative oil production of the A well is $68.6 \mathrm{~mL}$, and the final recovery degree is $28.31 \%$. The water drive stage is over. The D well is injected with active water, and the A, $\mathrm{B}$, and $\mathrm{C}$ wells are used as production wells. At the initial stage of active water injection, the total water cut decreases to $72.25 \%$. When $1.9 \mathrm{HCPV}$ is injected accumulatively, the A well is thoroughly watered out and closed, water flooding is completed, and the final recovery degree of the active water flooding stage is $6.0 \%$.
In the bottom water drive stage, the water breakthrough in the middle and upper wells is slow, the recovery degree is high, $24.85 \%$, and the contribution rate is $87.8 \%$. Due to the large control area of horizontal wells, there is no characteristic of bottom water ridging, the oil-water interface advances upward evenly, and the recovery degree is high in the water drive stage. In the active water flooding stage, the production differential pressure first increased to $0.37 \mathrm{MPa}$. It then decreased to $0.31 \mathrm{MPa}$, indicating that after the active water injected from the D well enters the simulated reservoir, the sweep range is improved, the plane and vertical displacement effects are apparent, and the remaining oil in the upper part of the middle and upper horizontal section can be fully utilized, as shown in Fig. 16.

\section{Alternate gas foam flooding experiment in the original well of the 943 reservoir}

The third group of the 943 reservoir original gas foam drive experiment is the physical model shown in Fig. 12a. The total volume of the experimental rock plate is $3600 \mathrm{~mL}$, the pore volume is $810 \mathrm{~mL}$, the hydrocarbon 


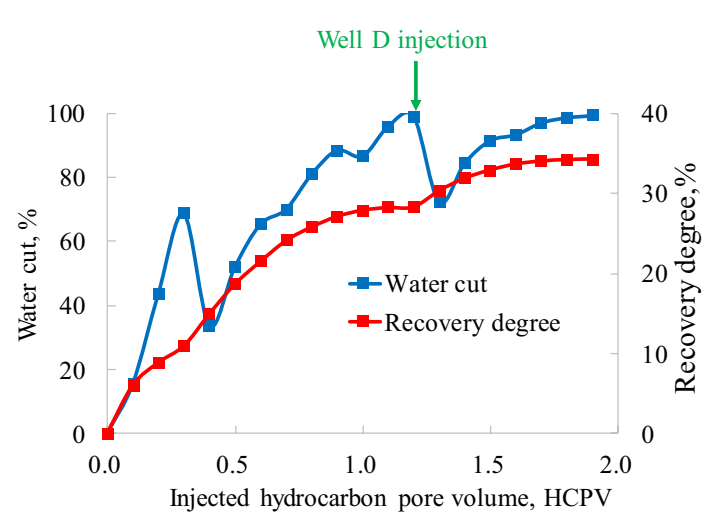

(a) Water cut and cumulative recovery vary with the pore volume of injected hydrocarbons

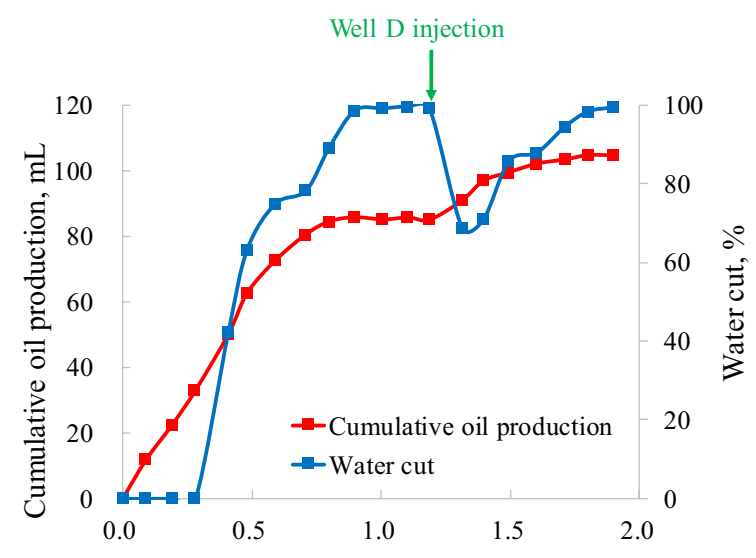

Injected hydrocarbon pore volume, HCPV

(c) The cumulative oil production and water cut of the $B$ well vary with the pore volume of injected hydrocarbons

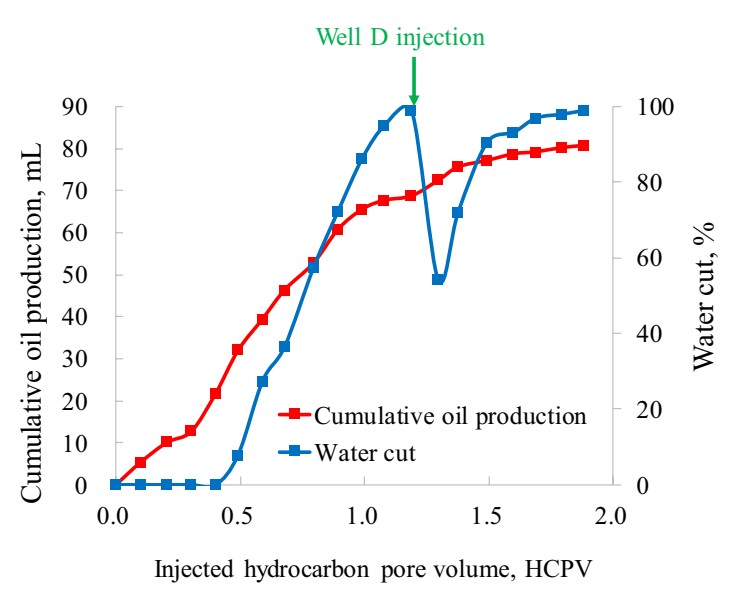

(b) The cumulative oil production and water cut of the A well vary with the pore volume of injected hydrocarbons

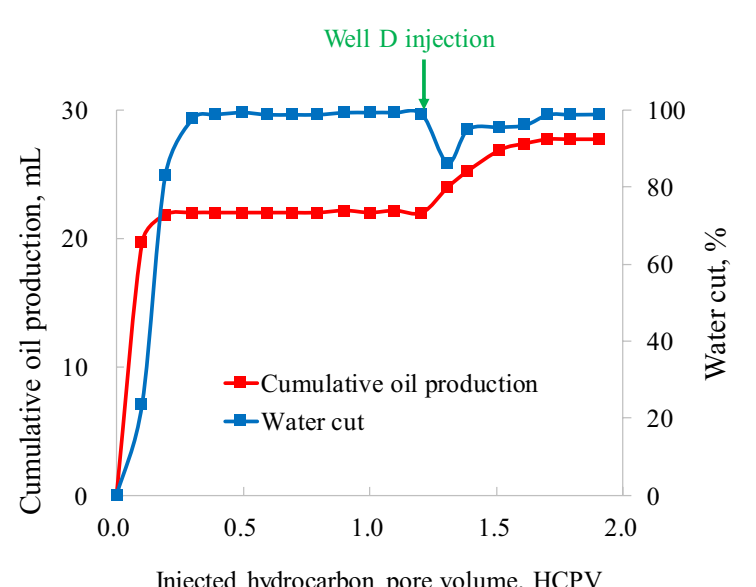

(d) The cumulative oil production and water cut of the $C$ well vary with the pore volume of injected hydrocarbons

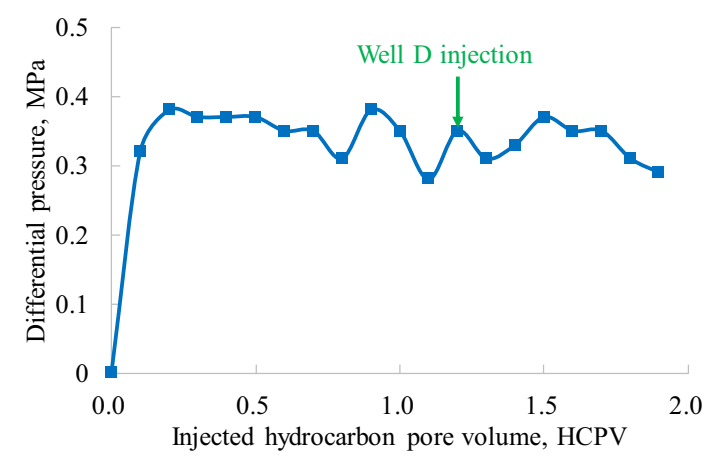

(e) Variation of production differential pressure with a pore volume of injected hydrocarbon in

the new well of the 943 reservoir

Fig. 15 Dynamic data change of active water displacement process in the new well of the 943 reservoir 


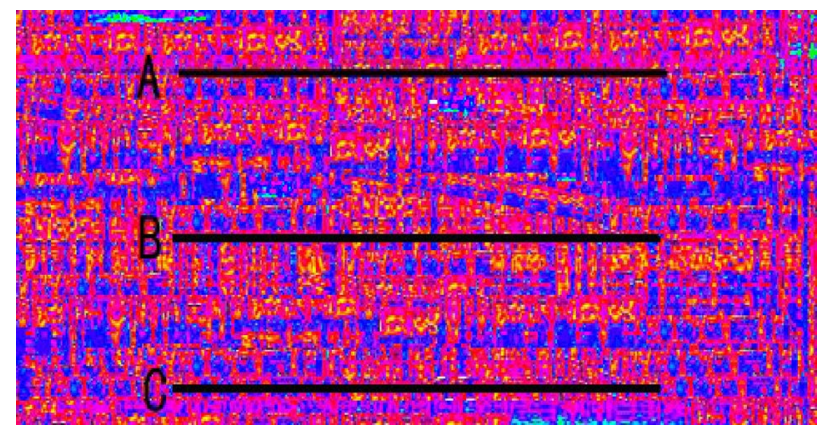

(a) Original rock sample

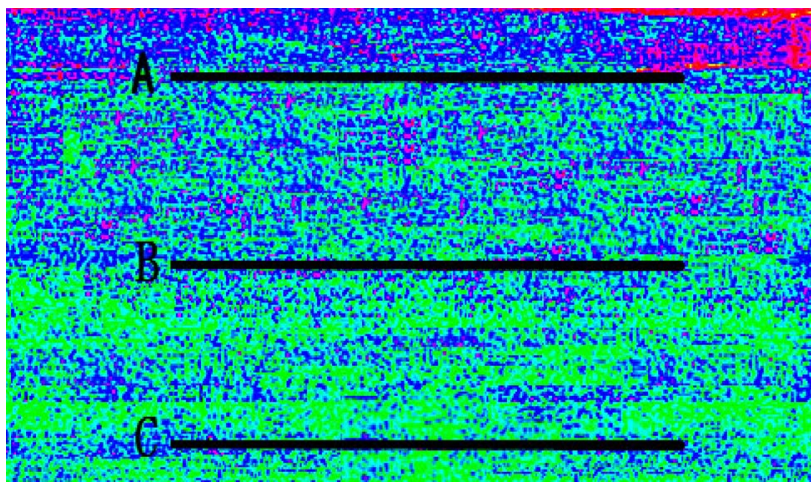

(b) End of water flooding

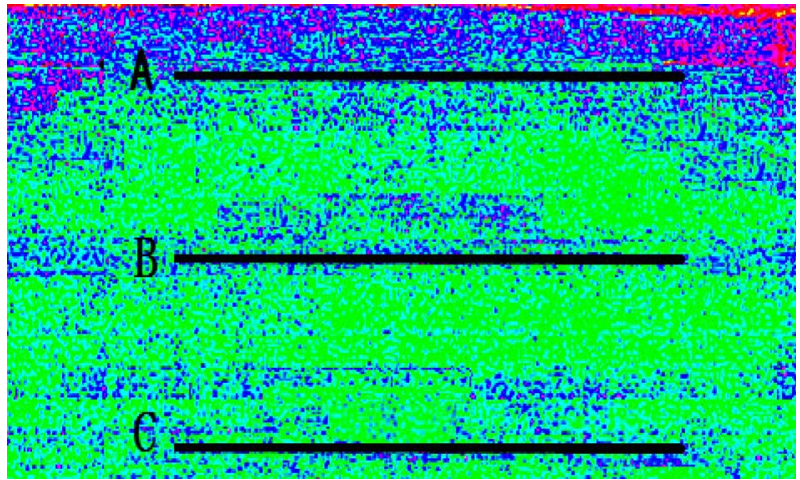

(c) End of active water flooding

Fig. 16 Active water displacement process in the new well of the 943 reservoir

pore volume is $665 \mathrm{~mL}$, and the bound water saturation is $18 \%$. In the water flooding stage, the bottom water displacement is injected at a constant speed from the bottom of the reservoir, and the displacement rate is $5 \mathrm{~mL} / \mathrm{min}$ : gas and foam alternate drive stage. The $0.1 \mathrm{HCPV}$ gas and foam are alternately injected from the well constant speed, and the injection rate is $5 \mathrm{~mL} / \mathrm{min}$. The experimental displacement data are shown in Table 11. The variation curves of water cut, cumulative recovery degree, cumulative oil production, and differential pressure with cumulative injected hydrocarbon pore volume during displacement are shown in Fig. 17. The displacement process scanned by XCT in the experiment is shown in Fig. 18.

When 1.5HCPV is injected accumulatively, the A well is completely flooded, and the A well is closed. End of water drive, and the final recovery degree is $28.05 \%$.

Alternately inject $0.1 \mathrm{HCPV}$ gas and foam from A well. At the initial stage of gas and foam alternate flooding, the total water cut decreases to $93 \%$. When the cumulative injection of $2.8 \mathrm{HCPV}$, the $\mathrm{C}$ well is thoroughly watered out and closed, the gas and foam alternately would be closed. At the same time, the final recovery rate of gas and foam alternate drive stage is $3.50 \%$ (Table 12 ).

In the bottom water drive stage, the water breakthrough in the middle and upper wells is slow, the recovery degree is high, $23.71 \%$, and the contribution rate is $84.56 \%$. The area controlled by the horizontal well is large, there is no characteristic of bottom water ridge, the oil-water interface advances upward, and the recovery degree is high in the water drive stage. During the alternate gas and foam flooding stage, the production pressure difference first increased to $0.37 \mathrm{MPa}$ and then decreased to $0.27 \mathrm{MPa}$, which shows that the foam can enter the simulated reservoir, block the large pores, and improve the sweep efficiency. During the middle and later stage of the chlorine foam, a small gas cap is formed in the upper part of the reservoir under the effect of gravity differentiation and foam profile control, and the remaining oil in the upper part of the injection well and the upper part of the production well is utilized to a certain extent. However, due to the large control area of the horizontal well, the gas channeling phenomenon occurs quickly in the gas cap. The remaining oil displacement at the top is not fully seen in Fig. 18, resulting in the absolute increase value of nitrogen foam flooding is not high.

\section{Summary}

In the active water displacement experiment of the original well of the 943 reservoir, after the active water injected into the A well enters the simulated reservoir, it mainly flows along the high water-bearing zone, and the spread range has not been improved. However, the vertical displacement effect is noticeable. The remaining oil in the upper part of the central horizontal section can be used, and the remaining oil in the upper part of the top horizontal section cannot be used. The final recovery degree of active water is $2.91 \%$. 
Table 11 Gas and foam displacement data in the original well of the 943 reservoir

\begin{tabular}{|c|c|c|c|c|}
\hline $\begin{array}{l}\text { Injected hydrocarbon pore } \\
\text { volume, HCPV }\end{array}$ & Injection medium & $\begin{array}{l}\text { Differential pres- } \\
\text { sure, } \mathrm{MPa}\end{array}$ & $\begin{array}{l}\text { Recovery } \\
\text { degree, } \%\end{array}$ & Water cut, $\%$ \\
\hline 0.1 & Formation water & 0.32 & 12.00 & 23.42 \\
\hline 0.2 & & 0.38 & 14.30 & 64.58 \\
\hline 0.3 & & 0.37 & 15.71 & 85.20 \\
\hline 0.4 & & 0.37 & 17.82 & 53.18 \\
\hline 0.5 & & 0.37 & 19.89 & 72.34 \\
\hline 0.6 & & 0.35 & 21.22 & 82.15 \\
\hline 0.7 & & 0.35 & 22.29 & 85.54 \\
\hline 0.8 & & 0.31 & 23.08 & 90.48 \\
\hline 0.9 & & 0.38 & 23.82 & 92.11 \\
\hline 1.0 & & 0.35 & 24.06 & 97.38 \\
\hline 1.1 & & 0.28 & 25.46 & 65.93 \\
\hline 1.2 & & 0.35 & 26.68 & 82.54 \\
\hline 1.3 & & 0.31 & 27.46 & 89.96 \\
\hline 1.4 & & 0.33 & 27.98 & 93.06 \\
\hline 1.5 & & 0.37 & 28.05 & 99.18 \\
\hline 1.6 & Foam & 0.33 & 28.20 & 96.77 \\
\hline 1.7 & Nitrogen & 0.31 & 28.41 & 93.81 \\
\hline 1.8 & Foam & 0.27 & 28.68 & 95.58 \\
\hline 1.9 & Nitrogen & 0.29 & 28.86 & 93.81 \\
\hline 2.0 & Foam & 0.35 & 29.26 & 92.58 \\
\hline 2.1 & Nitrogen & 0.37 & 29.67 & 90.04 \\
\hline 2.2 & Foam & 0.37 & 30.80 & 8509 \\
\hline 2.3 & Nitrogen & 0.35 & 30.86 & 97.80 \\
\hline 2.4 & Foam & 0.37 & 31.34 & 93.40 \\
\hline 2.5 & Nitrogen & 0.37 & 31.37 & 97.30 \\
\hline 2.6 & Foam & 0.35 & 31.46 & 93.33 \\
\hline 2.7 & Nitrogen & 0.38 & 31.53 & 95.80 \\
\hline 2.8 & Nitrogen & 0.31 & 31.55 & 99.29 \\
\hline
\end{tabular}

In the active water displacement experiment of the new well, the 943 reservoir, after the active water injected from the D well enters the simulated reservoir, the sweep range is improved, the plane and vertical displacement effect are apparent, and the remaining oil in the upper part of the middle and upper horizontal section can be fully utilized. The final recovery degree of activated water is $6.0 \%$.

When the 943 reservoir gas and foam alternate drive stage, the foam can enter the simulated reservoir and block the large pores, thus improving the sweep efficiency. During the middle and later stage of the chlorine foam, a small gas cap is formed in the upper part of the reservoir under the effect of gravity differentiation and foam profile control, and the remaining oil in the upper part of the injection well and the upper part of the production well is utilized to a certain extent. However, due to the large control area of the horizontal well, the gas channeling phenomenon occurs quickly at the gas cap, and the surplus oil is not enough for the top, resulting in the absolute increase value of nitrogen foam flooding is not high. At this time, the final recovery rate of gas and foam alternately is $3.50 \%$. 


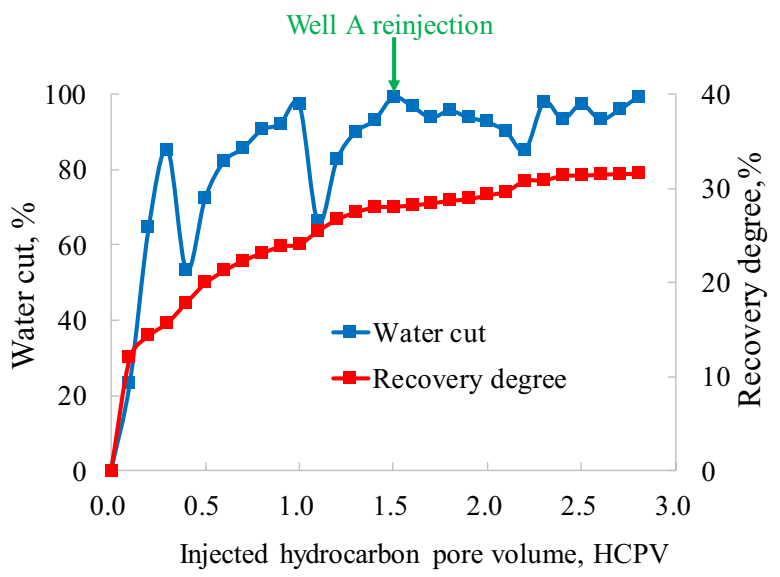

(a) Water cut and cumulative recovery vary with the pore volume of injected hydrocarbons

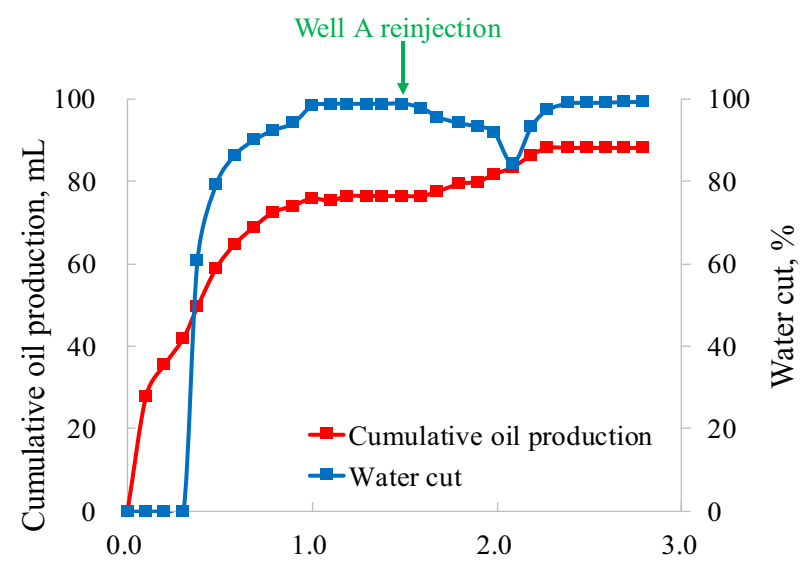

Injected hydrocarbon pore volume, HCPV

(c) The cumulative oil production and water cut of the $B$ well vary with the pore volume of injected hydrocarbons

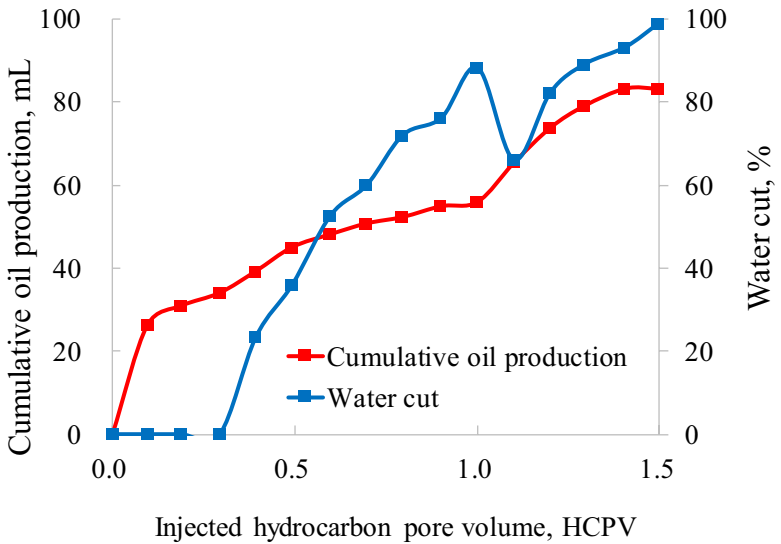

(b) The cumulative oil production and water cut of the A well vary with the pore volume of injected hydrocarbons

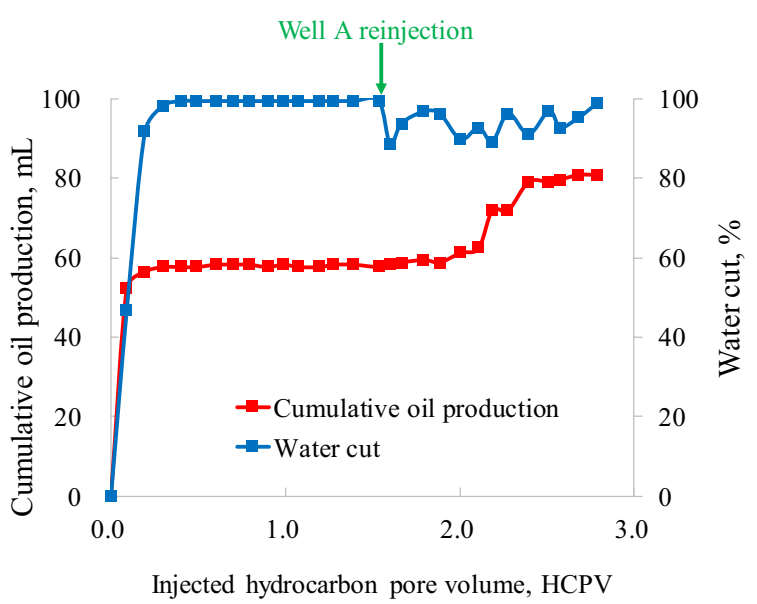

(d) The cumulative oil production and water cut of the $C$ well vary with the pore volume of injected hydrocarbons

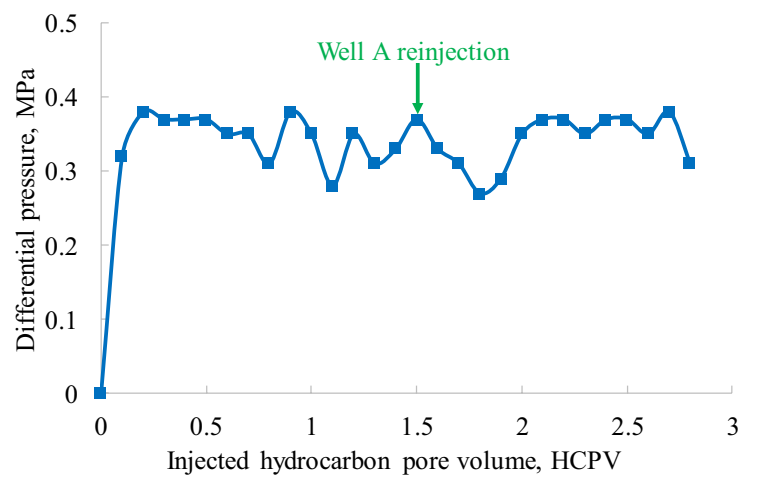

(e) Variation of production differential pressure with a pore volume of injected hydrocarbon

Fig. 17 Dynamic data change of gas foam alternate displacement in the original well of the 943 reservoir

\section{Conclusions}

(1) The gas and foam alternate flooding method is better than the active water drive for the remaining oil between sand bodies. Moreover, gas and foam alternate flooding can use inter-well residual oil for heavy oil reservoirs, increasing the oil recovery by $12.44 \%$. It is found that the injected foam can seal the high permeability layer to a certain extent 


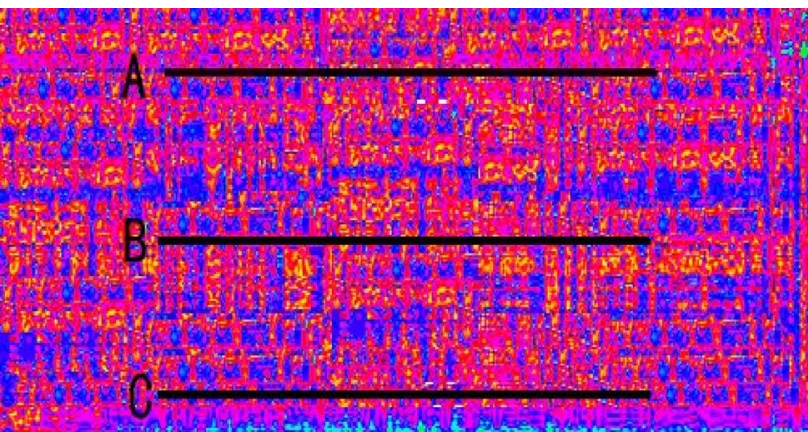

(a) Original rock sample

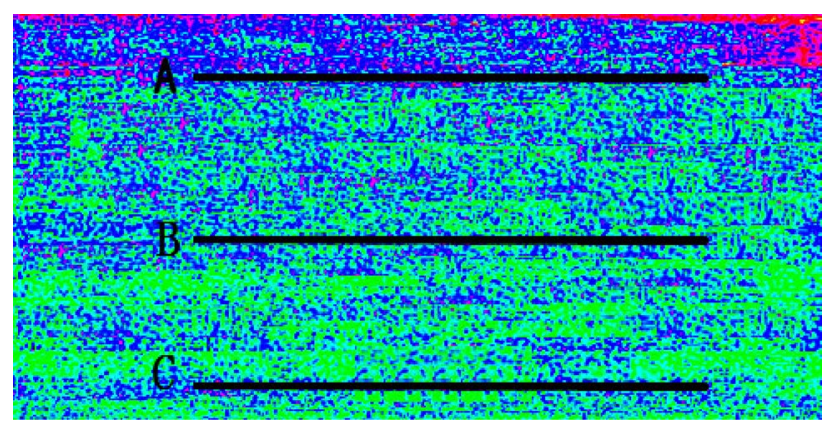

(b) End of water flooding

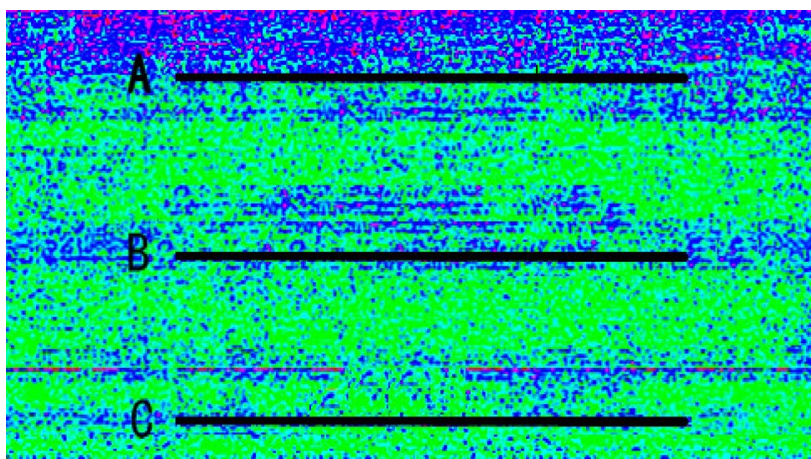

(c) End of gas foam alternate flooding

and enlarge the swept area. The active substances in the foam can change the tension at the oil-water interface and improve the recovery level. The injected gas can form a gas cap drive at the top of the reservoir to replace the remaining oil between wells.

(2) because of the remaining oil at the top of the reservoir, the method of injecting gas and foam alternately to drive new wells in the upper reservoir can better utilize the remaining oil at the top of the reservoir. The research shows that due to the large control area of horizontal wells, the recovery degree is high in water flooding, and the remaining oil is enriched at the top and edge of the reservoir. When the active water is injected from the original well, the vertical displacement is apparent, the remaining oil in the upper part of the central horizontal section can be used, and the remaining oil at the top can not be used. When the gas and foam are alternately driven from the original well, the foam enters the reservoir, blocking the large pores and improving sweep efficiency. Under the influence of gravity differentiation, the gas floating and downward foam flooding, the remaining oil injected into the upper part of the well, and the upper part of the production well is utilized to a certain extent. When the gas bubble was injected from $\mathrm{Nii}$, the sweep efficiency was significantly improved, and the vertical and horizontal displacement was apparent. The remaining oil in the upper part of the reservoir could be used, and the recovery of the oil reservoir increased by $6.00 \%$.

This experimental study guides tapping the potential of the remaining oil in the offshore strong bottom water reservoir.

Fig. 18 Alternate gas foam flooding process of in original well of the 943 reservoir

Table 12 Physical simulation experiment results of top residual oil displacement production

\begin{tabular}{lll}
\hline Displacement mode & $\begin{array}{l}\text { Injection medium } \\
\text { Oil displacement of active water injected into original wells of the } 943 \text { reservoir }\end{array}$ & $\begin{array}{l}\text { Formation water } \\
\text { degree, } \%\end{array}$ \\
\hline Oil displacement data of active water injected into new wells of the 943 reservoir & Formation water & Active water \\
Gas and foam displacement in the original well of the 943 reservoir & Formation water & Gas foam alternate \\
\hline
\end{tabular}


Funding The Project is supported by the National Science and Technology Major Project During The 13th Five-year Plan Period "Bohai Oilfield Efficient Development Demonstration Project" (Number 2016ZX05058). The funders had no role in study design, data collection, analysis, decision to publish, or manuscript preparation.

\section{Declarations}

Conflict of interest On behalf of all authors, the corresponding author states that there is no conflict of interest.

To be used for non-life science journals.

Open Access This article is licensed under a Creative Commons Attribution 4.0 International License, which permits use, sharing, adaptation, distribution and reproduction in any medium or format, as long as you give appropriate credit to the original author(s) and the source, provide a link to the Creative Commons licence, and indicate if changes were made. The images or other third party material in this article are included in the article's Creative Commons licence, unless indicated otherwise in a credit line to the material. If material is not included in the article's Creative Commons licence and your intended use is not permitted by statutory regulation or exceeds the permitted use, you will need to obtain permission directly from the copyright holder. To view a copy of this licence, visit http://creativecommons.org/licenses/by/4.0/.

\section{References}

Andrews AB, Mcclelland A, Korkeila O et al (2011) Molecular orientation of asphaltenes and PAH model compounds in langmuirblodgett films using sum frequency generation spectroscopy. Langmuir 27:6049-6058

Austad, T., Strand, S., Hognesen, E., et al. Seawater as IOR Fluid in Fractured Chalk. Society of Petroleum Engineers (2005), SPE-93000-MS, 10 .

Bartels WB, Mahani H, Berg S et al (2019) Literature review of low salinity waterflooding from a length and time scale perspective. Fuel 236:338-353

Bhatia, J., Srivastava, J., Sharma, A., et al.(2014) Production performance of water alternate gas injection techniques for enhanced oil recovery: effect of WAG ratio, number of WAG cycles and the type of injection gas. Int. J Oil, Gas Coal Technol. 7(2), 132-151.

Cai, Z. The study on the relationship between pore structure and displacement efficiency. Petroleum Exploration and Development, (2000), 27(6): 45-46, 49.

Cobos JE, Sogaard EG (2020) Study of geothermal brine reinjection by microcalorimetry and core flooding experiments. Geothermics. 87:101863

Ese M, Kilpatrick PK (2004) Stabilization of Water-in-oil emulsions by naphthenic acids and their salts: model compounds, role of pH, and soap: acid ratio. J Dispersion Sci Technol 2S:253-261

Gupta R, Mohanty K (2011) Wettability alteration mechanism for oil recovery from fractured carbonate rocks. Transp Porous Media 87:635-652

He T, Lu S, Li W et al (2018) Effect of salinity on source rock formation and its control on the oil content in shales in the Hetaoyuan formation from the biyang depression, nanxiang basin. Central China Energy Fuels 32(6):6698-6707

Hoteit ,H., Firoozabadi, A. Numerical modeling of diffusion in fractured media for gas-injection and recycling schemes. SPE (2009), 103292
Jacquelin EC, Erik GS (2020) Impact of compositional differences in chalk and water content on advanced water flooding: a microcalorimetrical assessment. Energy Fuels 34:12291-12300

Kumar M, Sharma P, Gupta DK (2018) Sensitivity study of horizontal length, offset from water oil contact and withdrawal rate of horizontal well in bottom water drive reservoir. J Petrol Explor Prod Technol 8:577-588. https://doi.org/10.1007/ s13202-017-0348-9

Lai SM (2018) Technology policy limitation of subdivision water injection in ultra-high water cut stage: a case from Shengli uncompartmentalized reservoirs. Lithologic Reserv 30(5):124-130

Li X, Krooss BM (2017) Influence of grain size and moisture content on the high-pressure methane sorption capacity of Kimmeridge Clay. Energy Fuels 31(11):11548-11557

Li XG, Sun CH, Zhao YF (2007) Research on variation rule of reservoir microscopic structures and features in Lamadian Oilfield. Petroleum Geol Oilfield Develop Daqing 21(1):79-82

Mahani H, Menezes R, Berg S et al (2017) Insights into the impact of temperature on the wettability alteration by low salinity in carbonate rock. Energy Fuels 31:7839-7853

Mancinelli R, Botti A, Bruni F et al (2007) Perturbation of water structure due to monovalent ions in solution. Phys Chem Chem Phys 9:2959-2967

Mokhtari R, Ayatollahi S (2019) Dissociation of polar oil components in low salinity water and its impact on crude oil-brine interfacial interactions and physical properties. Pet Sci 16:328

Moradi M, Topchiy E, Lehmann TE et al (2013) Impact of ionic strength on partitioning of naphthenic acids in water-crude oil systems-Determination through high-field NMR spectroscopy. Fuel 12:236-248

Myint PC, Firoozabadi A (2015) Thin liquid films in improved oil recovery from low-salinity brine. Curr Opin Colloid Interface Sci 20:105-114

Nasralla, R., Snippe, J., Farajzadeh, R. Coupled Geochemical Reservoir Model to Understand the Interaction Between Low Salinity Brines and Carbonate Rock. SPE Asia Pacific Enhanced Oil Recovery Conference held in Kuala Lumpur, Malaysia, (2015); $\mathrm{p} 21$.

Peng J, Kang YL (2008) Effect of wettability and its evolution on oil reservoir recovery. Petroleum Geology and Recovery Efficiency 15(1):72-76

Puntervold T, Strand S, Ellouz R et al (2015) Modified seawater as a smart EOR fluid in chalk. J Pet Sci Eng 133:440-443

Sharma P, Kumar M, Gupta DK (2019) 3D numerical simulation of clastic reservoir with bottom water drive using various ior techniques for maximizing recovery. J Petrol Explor Prod Technol 9:1075-1087. https://doi.org/10.1007/s13202-018-0523-7

Tran TV, Truong TA, Ngo AT et al (2019) A case study of gascondensate reservoir performance under bottom water drive mechanism. J Petrol Explor Prod Technol 9:525-541. https:// doi.org/10.1007/s13202-018-0487-7

Xu X, Saeedi A, Liu K (2016) Laboratory studies on CO2 foam flooding enhanced by a novel amphiphilic ter-polymer Pet. Sci Emg 138:153-159

Zhang S, She Y, Gu Y (2011) Evaluation of polymers as direct thickeners for $\mathrm{CO} 2$ enhanced oil recovery. J Chem Eng Data 56(4):1069-1079

Zhu CS, Cheng LS (2007) Evaluation of enhanced oil recovery by $\mathrm{CO} 2$ flooding in low permeability reservoirs. Drill Prod Technol 6(30):55-60 